\title{
Recent Advances in Vertically Aligned Nanocomposites with Tunable Optical Anisotropy: Fundamentals and Beyond
}

\author{
Xuejing Wang ${ }^{1}$ and Haiyan Wang ${ }^{1,2, *(D)}$ \\ 1 School of Materials Engineering, Purdue University, West Lafayette, IN 47907, USA; xuejing@lanl.gov \\ 2 School of Electrical and Computer Engineering, Purdue University, West Lafayette, IN 47907, USA \\ * Correspondence: hwang00@purdue.edu
}

Citation: Wang, X.; Wang, H. Recent

Advances in Vertically Aligned

Nanocomposites with Tunable

Optical Anisotropy: Fundamentals and Beyond. Chemosensors 2021, 9 ,

145. https://doi.org/10.3390/

chemosensors 9060145

Academic Editor: Kandammathe

V. Sreekanth

Received: 21 April 2021

Accepted: 10 June 2021

Published: 16 June 2021

Publisher's Note: MDPI stays neutral with regard to jurisdictional claims in published maps and institutional affiliations.

Copyright: (c) 2021 by the authors. Licensee MDPI, Basel, Switzerland. This article is an open access article distributed under the terms and conditions of the Creative Commons Attribution (CC BY) license (https:/ / creativecommons.org/licenses/by/ $4.0 /)$.

\begin{abstract}
Developing reliable and tunable metamaterials is fundamental to next-generation opticalbased nanodevices and computing schemes. In this review, an overview of recent progress made with a unique group of ceramic-based functional nanocomposites, i.e., vertically aligned nanocomposites (VANs), is presented, with the focus on the tunable anisotropic optical properties. Using a selfassembling bottom-up deposition method, the as-grown VANs present great promise in terms of structural flexibility and property tunability. Such broad tunability of functionalities is achieved through VAN designs, material selection, growth control, and strain coupling. The as-grown multiphase VAN films also present enormous advantages, including wafer scale integration, epitaxial quality, sharp atomic interface, as well as designable materials and geometries. This review also covers the research directions with practical device potentials, such as multiplex sensing, hightemperature plasmonics, magneto-optical switching, as well as photonic circuits.
\end{abstract}

Keywords: vertically aligned nanocomposite (VAN); metamaterial; tunability; pulsed laser deposition (PLD); optical anisotropy

\section{Optical Anisotropy}

Optical anisotropy can be defined as the differences of complex refractive indices along the principal axes when light propagates through media [1]. Photonic crystals possessing birefringence or dichroism phenomena are considered as natural anisotropic media, but are either too bulky or present with limited birefringence [2-4]. Research continue developing structures with broken symmetry, such as layered two-dimensional crystals or transition metal dichalcogenides (TMDs) [5-7], as well as artificially constructed nanostructures or the so-called metamaterials that surpass the conventional limit in achieving extreme anisotropy at controlled frequencies [8-10].

Hyperbolic metamaterial (HMM) is one representative anisotropic medium that displays hyperboloid topologies (Figure $1 b, c$ ) at $k$-space, as opposed to the normal isotropic media (Figure 1a) [11-13]. Such anisotropy is normally achieved by coupling dielectric and metallic components at nanoscale as wire-in-matrix or multilayered schemes, which find applications in sensing, spontaneous emission, negative refraction, or designs of superlenses [14-16]. The multilayered HMMs can be further patterned into double-fishnet nanostructures (Figure 1c) for tunable negative refraction, or nanoresonator array (Figure 1d) that is completely fabricated with semiconductor candidates [17-21]. Wire metamaterial, on the other hand, provides additional flexibility, such as density or distribution (Figure 1f), aspect ratio, as well as geometry of the nanowires [8,22-25]. Contrary to the metallic nanowire in dielectric matrix configuration, the plasmonic nanohole structure (Figure $1 \mathrm{~g}$ ) can be considered as periodic "air" $(n=1)$ holes being embedded in the plasmonic media, which has been intensively explored for microfluidic sensing and superlenses [26-29]. Overall, the concept of building artificial nanostructures has already been implemented in multifunctional metamaterials toward sensing, ultrafast switching, spintronics, and 
neuromorphic computing [30-33]. For example, plasmonics sensors built by active metamaterials or metasurfaces have been demonstrated with controllable detection frequencies and detection limits that are crucial to biomedical and nanophotonic devices [34,35].

(a)

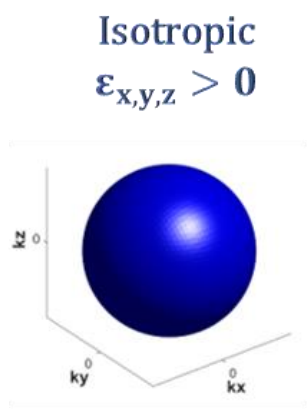

(b)

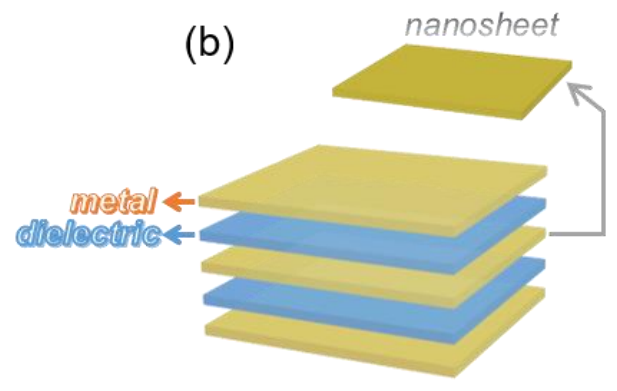

(e)

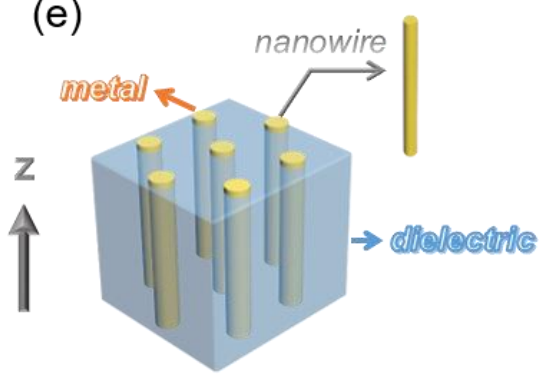

Type I HMM

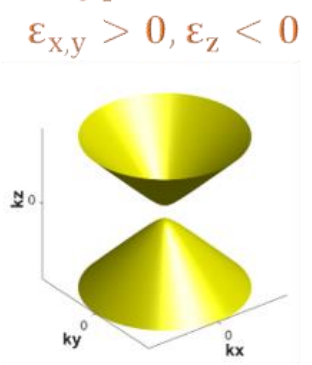

(c)

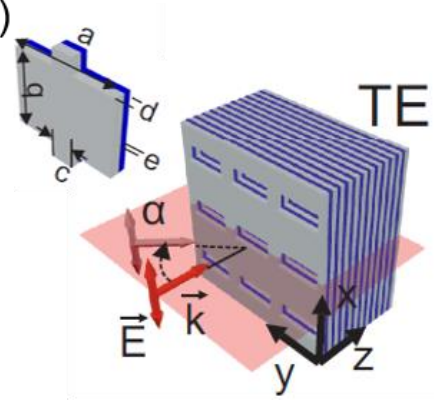

(f)

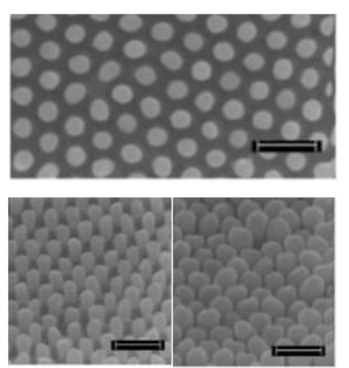

Type II HMM

$$
\varepsilon_{\mathrm{x}, \mathrm{y}}<0, \varepsilon_{\mathrm{z}}>0
$$

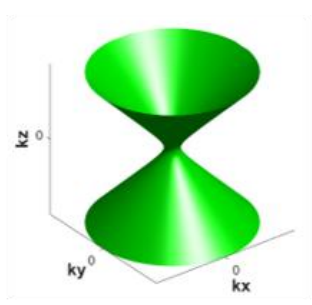

(d)

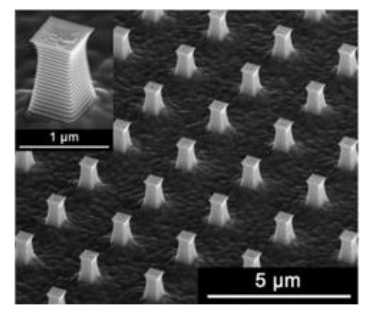

(g)

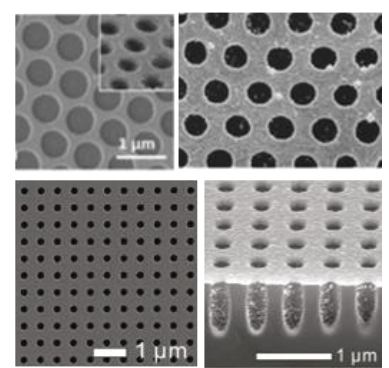

Figure 1. Optical metamaterials realizing extreme anisotropy. (a) $k$-space topologies of isotropic $\left(\varepsilon_{x, y, z}>0\right)$ materials, Type I $\left(\varepsilon_{x, y}>0, \varepsilon_{z}<0\right)$ and Type II $\left(\varepsilon_{x, y}<0, \varepsilon_{z}>0\right)$ HMMs. (b) Illustration of multilayer structure composed of metal and dielectric components. (c) Fishnet and (d) metasurface designs based on multilayered HMMs [19,21]. (e) Illustration of nanowire metamaterial composed of metal nanowires with dielectric matrix. (f) $\mathrm{Ag}$ nanowires in $\mathrm{Al}_{2} \mathrm{O}_{3}$ matrix [24]. (g) Metallic nanohole array [28,29]. Reproduced with permission, ACS Publications, Wiley, and The Optical Society.

\section{Nanostructure Fabrication}

Realizing as-proposed metamaterial designs for demanding nanodevice applications poses challenges to the existing fabrication techniques. Electron beam lithography (EBL), one of the most favorable methods of fabricating pre-designed metasurfaces with improved yield and resolution, is still limited by a small patterning area and relatively high cost $[36,37]$. An alternative method to fabricate wire metamaterial is to use an anodized alumina (AAO) template. By filling a secondary phase, such as metals or semiconductors, into the template using bottom-up deposition, this method is capable of producing nanorod arrays with a hexagonal order [38,39]. Both methods are capable of realizing sharp features or pattern size down to around $20 \mathrm{~nm}$.

Recently, conventional thin film growth methods are gaining importance in fabricating nanocomposites or heterostructures that are comparable to the HMM geometries. A multilayered structure or superlattice can be easily achieved by alternating between two sources or targets (Figure 2a) using magnetron sputtering, pulsed laser deposition (PLD), 
or molecular beam epitaxy (MBE) [40,41]. However, nanowire-in-matrix formation is more challenging considering multiple factors, including strain and lattice mismatch, wettability, and thermal stability between the two constituent phases. These factors are crucial to ensure well-shaped nanopillars and a sharp vertical interface without cation or inter-phase mixing. The wire-in-matrix configuration is also termed as vertically aligned nanocomposites (VANs), and has been realized in a wide range of oxide-oxide material systems, where one oxide phase is served as either nanopillars or nanodomains within another oxide matrix. These oxide-oxide VANs exhibit tunable multifunctionalities, such as magnetoresistance, superconductivity, and multiferroic properties [42-49]. The growth mechanism of VANs can be briefly explained as a self-assembled nucleation and growth The target is typically composed of a mixture of two material components with pre-defined volume or weight ratio. During the growth, the matrix phase favors the layered growth mode (Frank-van der Merwe) while the secondary phase, with lower concentration, favors islanded (Volmer-Weber) or mixed growth mode (Stranski-Krastanov) (Figure 2b) [50]. The resulted width and height of the nanopillars are typically determined by the size of nucleation and thin film thickness.
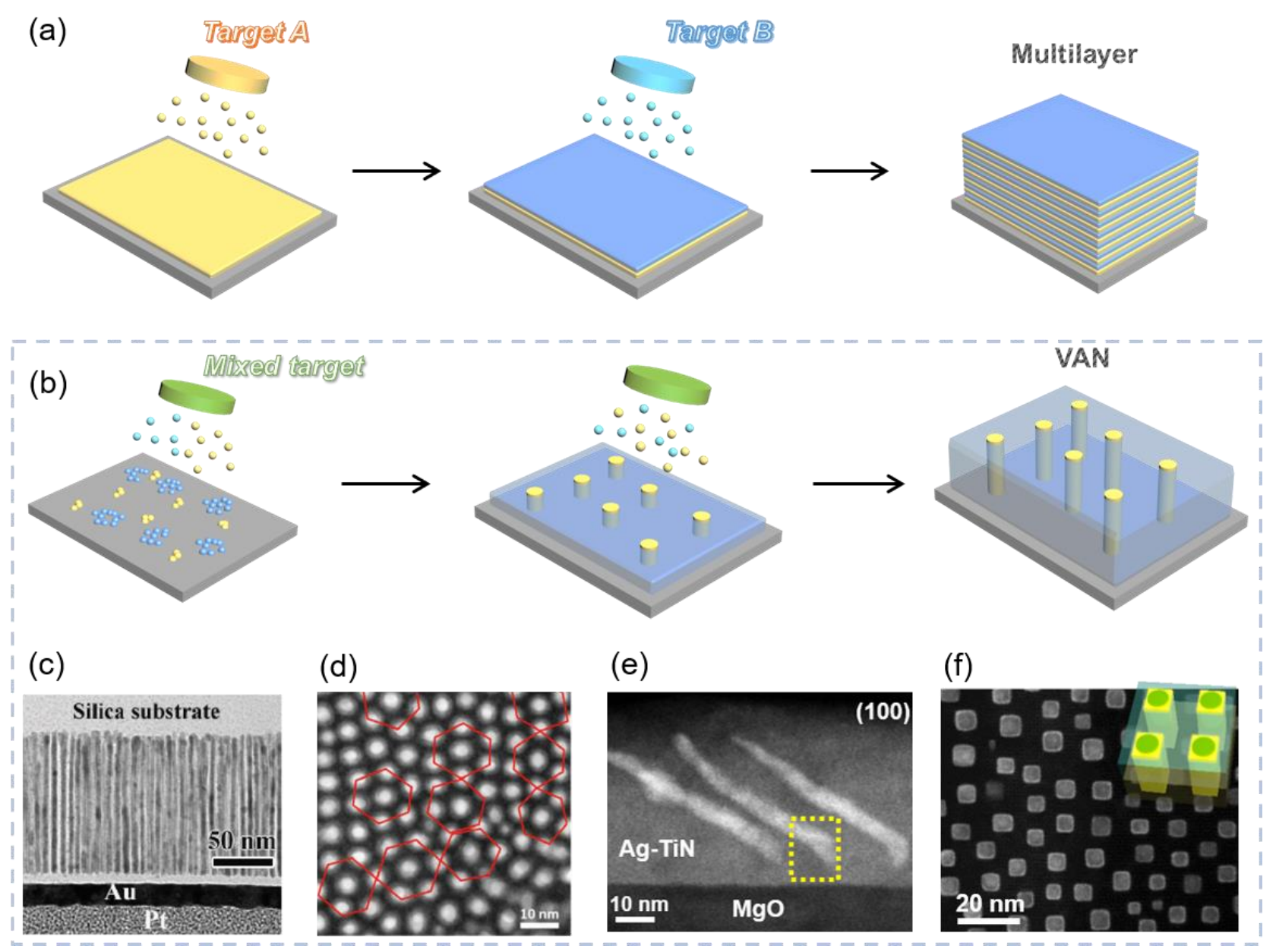

Figure 2. Processing of (a) multilayered heterostructure or metamaterial, (b) vertically aligned nanocomposite or metamaterial. (c) Ag nanowires in silica matrix [51], (d) Au nanopillars in TaN matrix [52], (e) tilted Ag nanopillars in TiN matrix [53], (f) highly ordered core-shell nanopillars in TiN matrix [54]. Reproduced with permission, Wiley.

Very recently, such bottom-up self-assembly has been extended to the coupling of ceramic and metals. Compare to oxide-oxide systems, involving metals brings several benefits, including (1) strong optical (e.g., Au, Ag) and magnetic (e.g., Co, Ni) properties that are drastically different from most oxides, (2) high surface energy leads to the islanded growth mode of metals as pillar-like or wire-like structures [55], (3) comparable crystal 
lattice and symmetry to those of oxides, which ensure a well-coupling at the film/substrate or pillar/matrix interface. Since the first success achieved in $\mathrm{BaTiO}_{3}-\mathrm{Au}$ VAN growth in 2016 [56], extensive research studies have been focused on exploring the growth mechanism, possible geometrical tunability, as well as material candidates. Examples include Ag nanowires in silica and alumina matrices (Figure 2c) [51], hexagonal-ordered Au nanopillars within TaN matrix (Figure 2d) [52], tilted Ag nanopillars in TiN matrix (Figure 2e) [53], as well as a highly ordered core-shell three-phase heterostructure (Figure 2f) [54]. All of these examples have shown great potentials in achieving various artificial metamaterial designs possessing relatively good periodicity, large-scale surface coverage, epitaxial quality, atomic-sharp interface, as well as tunable functionalities. Table 1 summarizes the recent ceramic-based wire metamaterials (or VANs) grown by physical vapor deposition technique, and their reported functionalities [51-54,56-74]. The ultimate goal is to realize an alternative method in fabricating functional heterostructures or metamaterials for applications including sensing, high-temperature plasmonics, nonlinear optics, ultrafast switching, as well as fundamental explorations, including tunable plasmonics or coupled multifunctionalities, using these highly anisotropic media.

Following the outline from Figure 3, this review covers recent advances on ceramicbased VAN metamaterials that realize tunable optical anisotropy and some additional functionalities. Selection rules for material candidates and how optical anisotropy is realized through the designs are discussed in Section 1. The atomic-scale strain coupling from the three-dimensional perspective will be covered as well to explain the formation mechanisms of such vertical aligned geometry (Section 1). Geometrical and substrate tuning and their effects on functionalities will be followed (Section 2). Additional capabilities such as sensing, magneto-optical coupling and thermal-stable plasmonics are reviewed in the Section 3. Challenges and future prospects will be discussed at the end of this review (Section 4).

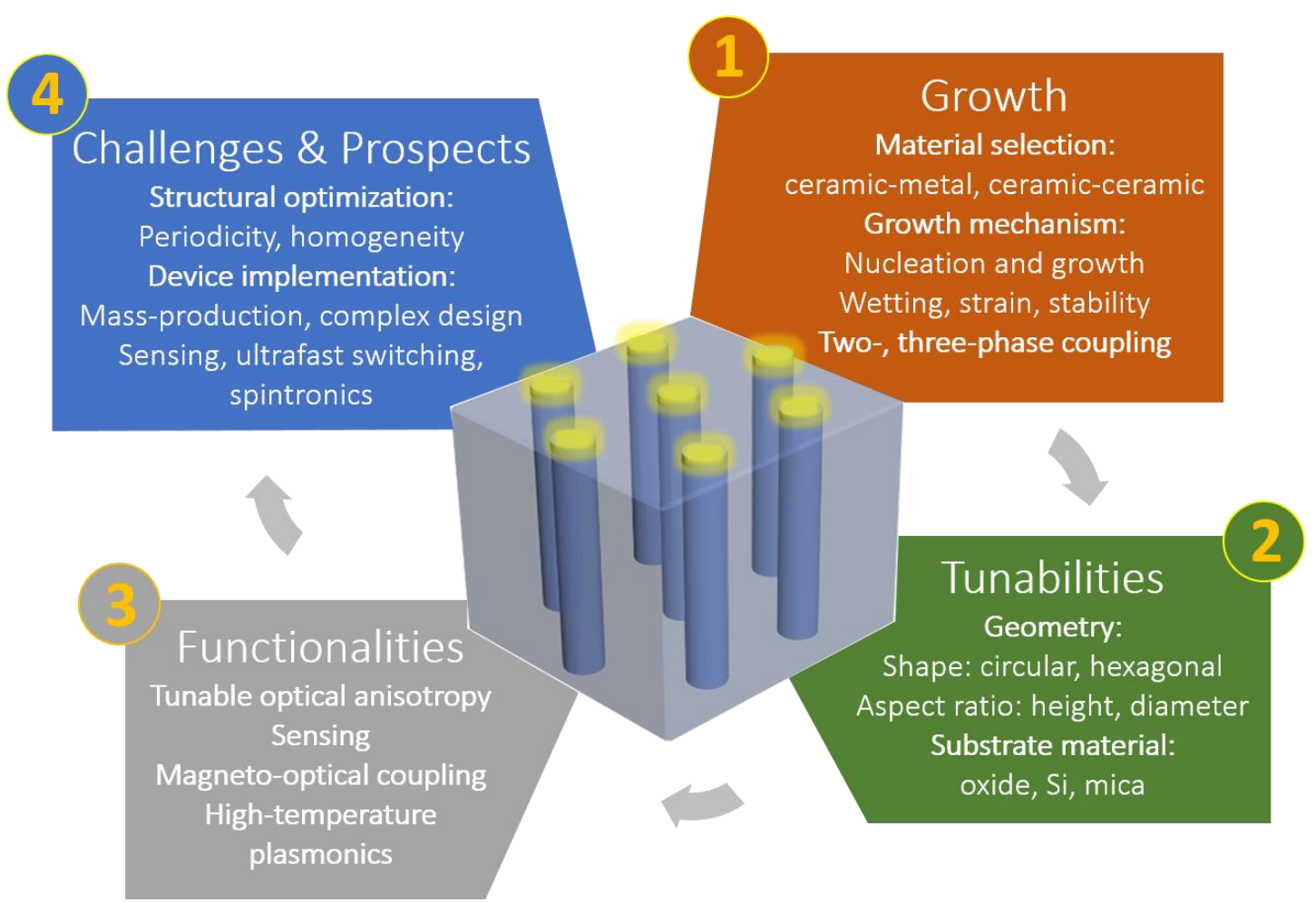

Figure 3. Outline. Section 1. Growth: material selection, growth mechanism, two-phase and three-phase coupling. Section 2. Tunability: geometry and substrate material. Section 3. Functionalities: tunable optical anisotropy, sensing, magneto-optical coupling, high-temperature plasmonics. Section 4. Challenges and prospects: structural optimization and device implementation. 
Table 1. Ceramic-based VANs grown by PLD.

\begin{tabular}{|c|c|c|c|c|c|}
\hline Matrix Phase & Pillar Phase (2nd) & Additional Phase (3rd) & Substrate Material & Key Functionalities & Reference \\
\hline $\mathrm{Al}_{2} \mathrm{O}_{3}$ & \multirow{2}{*}{$\mathrm{Ag}$} & \multirow{2}{*}{-} & \multirow{2}{*}{$\mathrm{SiO}_{2}$} & \multirow{2}{*}{$\begin{array}{l}\text { Plasmonic resonance, strong } \\
\text { optical absorption }\end{array}$} & \multirow{2}{*}[51]{} \\
\hline $\mathrm{SiO}_{2}$ & & & & & \\
\hline \multirow{3}{*}{$\mathrm{BaTiO}_{3}(\mathrm{BTO})$} & $\mathrm{Au}$ & - & $\begin{array}{l}\mathrm{SrTiO}_{3}(\mathrm{STO}) \\
\mathrm{Si}(\mathrm{TiN} / \mathrm{STO} \\
\text { buffer), Mica }\end{array}$ & $\begin{array}{l}\text { Tunable pillar dimension, } \\
\text { thermal stability, } \\
\text { hyperbolic, ferroelectric }\end{array}$ & {$[56-60]$} \\
\hline & Au-Ag alloy & - & $\mathrm{STO}, \mathrm{MgO}$ & Hyperbolic & {$[61]$} \\
\hline & $\mathrm{Au}$ & $\mathrm{ZnO}$ & $\begin{array}{c}\mathrm{STO}, \mathrm{MgO}, \\
\mathrm{LaAlO}_{3}(\mathrm{LAO})\end{array}$ & Hyperbolic & {$[62-64]$} \\
\hline \multirow{3}{*}{$\mathrm{ZnO}$} & $\mathrm{Au}$ & - & \multirow{2}{*}{$\mathrm{c}-\mathrm{Al}_{2} \mathrm{O}_{3}$} & $\begin{array}{c}\text { Tunable pillar } \\
\text { dimension, hyperbolic }\end{array}$ & {$[65]$} \\
\hline & Au-Ag alloy & - & & \multirow{2}{*}{ Low loss, hyperbolic } & {$[66]$} \\
\hline & $\mathrm{Cu}$ & - & $\mathrm{STO}, \mathrm{c}-\mathrm{Al}_{2} \mathrm{O}_{3}$ & & {$[67]$} \\
\hline $\begin{array}{l}\mathrm{La}_{0.67} \mathrm{Sr}_{0.33} \mathrm{MnO}_{3} \\
\quad(\mathrm{LSMO})\end{array}$ & $\mathrm{Au}$ & - & STO & Tunable pillar density, & {$[68]$} \\
\hline $\begin{array}{l}\mathrm{La}_{0.5} \mathrm{Sr}_{0.5} \mathrm{FeO}_{3} \\
\text { (LSFO) }\end{array}$ & $\mathrm{Au}$ & $\mathrm{Fe}$ & STO & Magneto-optical anisotropy & {$[69]$} \\
\hline $\mathrm{TaN}$ & $\mathrm{Au}$ & - & \multirow{2}{*}{$\mathrm{MgO}, \mathrm{STO}, \mathrm{Si}$} & $\begin{array}{l}\text { SHG, surface-enhanced } \\
\text { Raman scattering } \\
\text { (SERS) effect }\end{array}$ & {$[52]$} \\
\hline \multirow{5}{*}{$\mathrm{TiN}$} & $\mathrm{Au}$ & - & & $\begin{array}{l}\text { Tunable pillar density, SERS } \\
\text { effect, chemical sensing }\end{array}$ & {$[70,71]$} \\
\hline & $\mathrm{Ag}$ & - & $\mathrm{MgO}, \mathrm{c}-\mathrm{Al}_{2} \mathrm{O}_{3}$ & $\begin{array}{c}\text { Tunable pillar tilting, thermal } \\
\text { stability, angular } \\
\text { selectivity, SHG }\end{array}$ & [53] \\
\hline & Air & - & $\mathrm{MgO}$ & Sensing, optical anisotropy & {$[72]$} \\
\hline & $\mathrm{NiO}$ & - & $\mathrm{MgO}, \mathrm{Si}$ & $\begin{array}{c}\text { Tunable pillar } \\
\text { dimension, hyperbolic, } \\
\text { magneto-optical anisotropy }\end{array}$ & [73] \\
\hline & $\mathrm{NiO}$ & $\mathrm{Au}$ & $\mathrm{MgO}$ & Magneto-optical anisotropy & {$[54]$} \\
\hline
\end{tabular}

\section{Material Selection toward Optical Anisotropy}

As stated above, optical anisotropy is realized when light penetration varies along principal axes. To this end, candidates such as dielectrics and metals are considered due to their strong variation of dispersion property. Hyperbolic metamaterial certainly belongs to an extreme anisotropy scheme, where the signs of dielectric tensors along inplane (IP, or ordinary) and out-of-plane (OP, or extra-ordinary) are completely opposite at certain wavelength region. $\mathrm{BaTiO}_{3}(n=2.4)$ - $\mathrm{Au}$ on STO substrate is the first explored ceramic-metal VAN growth. The dominating factors of this successful VAN integration lies in (1) close match between BTO, Au and STO lattices, (2) stable growth of BTO under reduced oxygen pressure (vacuum), and (3) high thermal stability and easy nucleation of $\mathrm{Au}$. In terms of functionality, BTO exhibits ferroelectric property while Au exhibits strong plasmonic resonance at nanoscale [75]. As a result, the VAN structure exhibits distinct Au nanopillars and BTO matrix without intermixing or discontinuity $[56,76]$. The Au nanopillars possess a diameter of around $20 \mathrm{~nm}$ and a relatively uniform distribution as visualized from plan-view and cross-section energy-dispersive X-ray spectroscopy (EDX) mapping (Figure $4 \mathrm{~b}$ ). Effectively, the structure exhibits a Type I hyperbolic property at near infrared regime with epsilon-near-zero (ENZ) transition at $824 \mathrm{~nm}$ (Figure 4a). Such ENZ transition can be tuned and will be discussed later. 
(a)

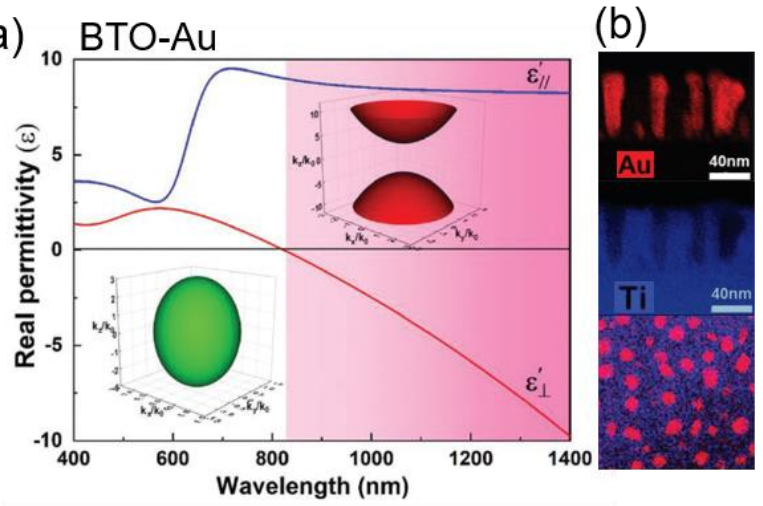

(e) TiN Nanohole

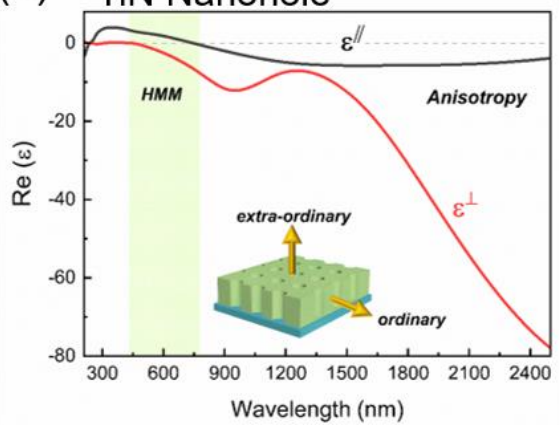

(f)

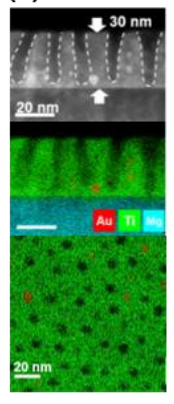

(c)

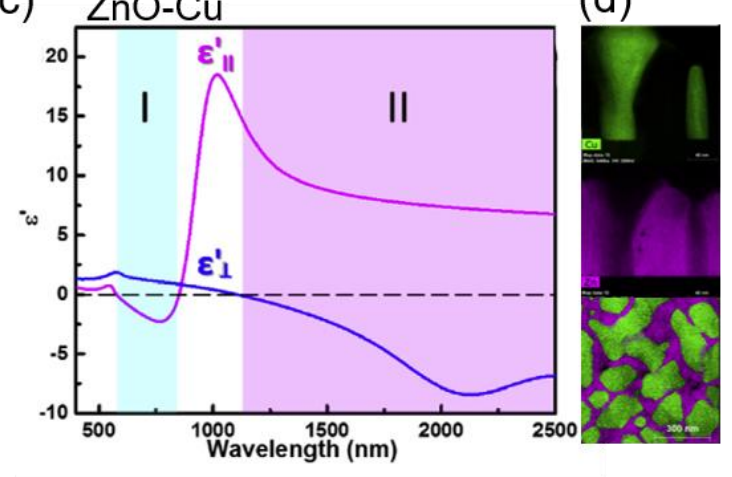

(g)

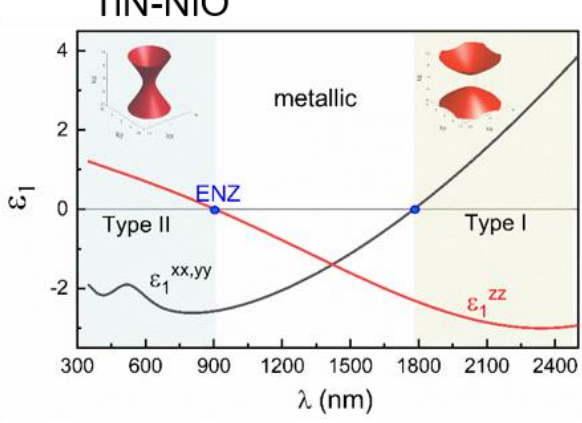

(h)

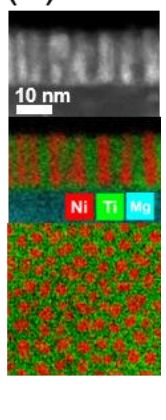

Figure 4. Uniaxial dielectric function and corresponding microstructures of VAN systems showing strong optical anisotropy. (a,b) BTO-Au VAN [57], (c,d) ZnO-Cu VAN [67], (e,f) TiN nanoholes [72], (g,h) TiN-NiO VAN [73]. Reproduced with permission, Wiley and ACS Publications.

The success of BTO-Au VAN paves the way for coupling a wide range of material candidates, for example, the $\mathrm{ZnO}$-metal VAN system. $\mathrm{ZnO}$ is an interesting dielectric candidate with piezoelectric and photocatalytic properties [77]. Figure 4c,d shows a reported $\mathrm{ZnO}-\mathrm{Cu}$ metamaterial where $\mathrm{Cu}$ nanocolumns or nanorods with dimensions around $100 \mathrm{~nm}$ are vertically distributed in $\mathrm{ZnO}$ matrix(Figure 4d) [67]. Compare to noble metals, $\mathrm{Cu}$ owns advantages such as cost-effectiveness and a strong localized surface plasmon (LSP) mode. Structurally, $\mathrm{ZnO}$ functions as a durable supporting matrix to prevent $\mathrm{Cu}$ from oxidation, while the $\mathrm{ZnO} / \mathrm{Cu}$ interface remains atomically sharp without intermixing. Similarly, optical anisotropy with two types of hyperbolic transition are visualized at 580 to $850 \mathrm{~nm}$ (Type II) and above $1100 \mathrm{~nm}$ (Type I).

Aside from oxide-based metamaterials, transition metal nitride-based metamaterials have been proposed that also hold optical anisotropy [74]. Here, the conductive titanium nitride (TiN) matrix demonstrates several unique characteristics, including high mechanical and thermal stabilities, and plasmonic property comparable to Au. Ideally, TiN becomes a desirable supporting matrix to embed unstable nanoresonators, and potentially, TiN can be an alternative candidate to replace lossy metallic components. Using a two-step growth and chemical etching process, an epitaxial TiN nanohole film has been reported. Here, the 6-nm "air gaps" (Figure 4f) generates strong optical anisotropy as represented by the ordinary and extraordinary dielectric tensors in Figure 4e [72]. Different from conventional methods of nanohole fabrication, such as EBL or laser imprinting, using bottom-up deposition of TiN-Au VAN followed by chemical etching to remove Au nanopillars produces large-scale throughput and ultrafine holes with reasonable ordering. The chemically inert TiN provides a natural diffusion barrier against strong etching acids and results in high crystalline quality and intact film morphology.

Furthermore, the idea has been extended to coupling all-ceramic candidates to grow hyperbolic metamaterial without metals. $\mathrm{TiN}-\mathrm{NiO}$ was the first explored heterostructure, 
considering the natural p-type semiconducting property of $\mathrm{NiO}$, as well as a close lattice match between $\mathrm{TiN}$ and $\mathrm{NiO}$ [78]. Interestingly, this heterostructure realizes a magnetooptical coupling considering the weak ferromagnetism generated in nanoscale $\mathrm{NiO}$ phase, which will be discussed at the end of this review. Results demonstrate an effective growth of $\mathrm{NiO}$ nanorods within $\mathrm{TiN}$ matrix (Figure $4 \mathrm{~h}$ ), with a tunable dimension by changing the pulsed laser frequency [73]. Optically, hyperbolic properties with one-fold $k$-space hyperboloid generated at (Figure $4 \mathrm{~g}$ ) below $900 \mathrm{~nm}$ and two-fold at above $1775 \mathrm{~nm}$ are confirmed. The success of growing VANs by coupling all-ceramic candidates opens tremendous opportunities since there are a wide range of functional oxides or carbides that can potentially be coupled to realize large-scale metamaterial fabrication within one-step growth.

\section{Strain Coupling and Growth Mechanisms of VANs}

Growth mechanisms of VANs, being intensively explored in oxide-oxide systems, are generally believed to be dominated by two mechanisms, i.e., nucleation and growth, and spontaneous decomposition $[45,48,79]$. Between the two mechanisms, the nucleation and growth mechanism covers most of the VAN self-assembly, which relies on a predefined volume ratio between the constituent phases, as well as inherit material properties such as wetting, lattice strain, as well as stability or immiscibility, which play the key role in determining the VAN growth and nucleation. Specifically, wetting or surface energy is the basis that dominates at the nucleation stage, which also shows a dependency on the crystalline plane. To realize a ceramic-metal VAN growth, the metallic phase usually favors the islanded growth mode while the oxide phase, contributing a higher volume ratio, prefers a layered growth mode [50]. In addition, lattice strain plays a role in controlling morphology and crystallinity, as in most cases, candidates with close lattice matching are considered. A third factor to consider is the stability, thermal stability is the major concern and is one crucial prerequisite for nanodevice integration. Any intermixing between the cations or any interdiffusion is not expected. These are the reasons why Au becomes the most favorable candidate as compared to metals that are easier to oxidize or melt like Aluminum.

As a result, the BTO-Au coupling is a typical example that meets the above three growth requirements. The lattice constant between Au $(a=4.080 A)$, BTO $(a=3.992 A)$ and STO substrate $(a=3.905 A)$ are so close that epitaxial coupling is facilitated along the vertical $\mathrm{BTO} / \mathrm{Au}$ interface as well as the lateral film/substrate interface. High resolution scanning transmission electron microscopy (HRSTEM) micrographs confirm the atomically sharp interface between $\mathrm{Au}$ and $\mathrm{BTO}$, and a smooth transition due to the ideal lattice match (Figure 5a-e). $\mathrm{La}_{0.67} \mathrm{Sr}_{0.33} \mathrm{MnO}_{3}$ (LSMO, $a=3.873 \mathrm{~A}$ ) is another perovskite candidate that can be coupled with Au as VAN, plus, LSMO is highly functional in terms of its magnetic and transport properties toward spintronic devices [80,81]. Results from Figure 5f,g indicate a crystalline sharp $\mathrm{LSMO} / \mathrm{Au}$ interface with two types of Au domains with a $45^{\circ}$ rotation [68]. Instead of squared-like pillar geometry for coupling between two cubic phases, the growth of $\mathrm{ZnO}$ and metal results in a hexagonal pillar geometry (Figure $5 \mathrm{~h}, \mathrm{i}$ ), which is affected by the three-fold symmetry of wurtzite $\mathrm{ZnO}$ and the supporting sapphire (c-cut) substrates. The metallic phase is orientated at (111) to match the symmetry and lattice spacing of (0002) $\mathrm{ZnO}$ and (0006) $\mathrm{Al}_{2} \mathrm{O}_{3}$.

Using the two-phase VANs as a well-ordered template, more complex heterostructures such as three-phase coupling by adding a small fraction of one additional component have been explored. For example, the growth of BTO-ZnO-Au VAN (Figure 5j,k) is achieved by using the BTO-Au VAN as the template layer to grow BTO-ZnO VAN [62]. Interestingly, as shown in Figure 5j, the unique "nanoman-like" nanostructure is affected by the "vaporliquid-solid (VLS)" growth mechanism [82,83], where Au nanorods at the bottom act as seeds for catalyzing $\mathrm{ZnO}$ nanowires, which are also capped on top. Similarly, the growth of a TiN-NiO-Au three-phase heterostructure is shown in Figure 51,m [54]. By applying the highly ordered TiN-Au VAN template, the $\mathrm{NiO}$ pillars being nucleated on top of Au exhibit significant enhancement of long-range ordering and homogeneity. Here, a special core 
$(\mathrm{NiO})$-shell $(\mathrm{Au})$ nanostructure is formed via a strain compensation mechanism where the upward diffusion of $\mathrm{Au}$ adatoms releases the strain energy between $\mathrm{TiN}$ and $\mathrm{NiO}$, forming the two-atomic layer shell.

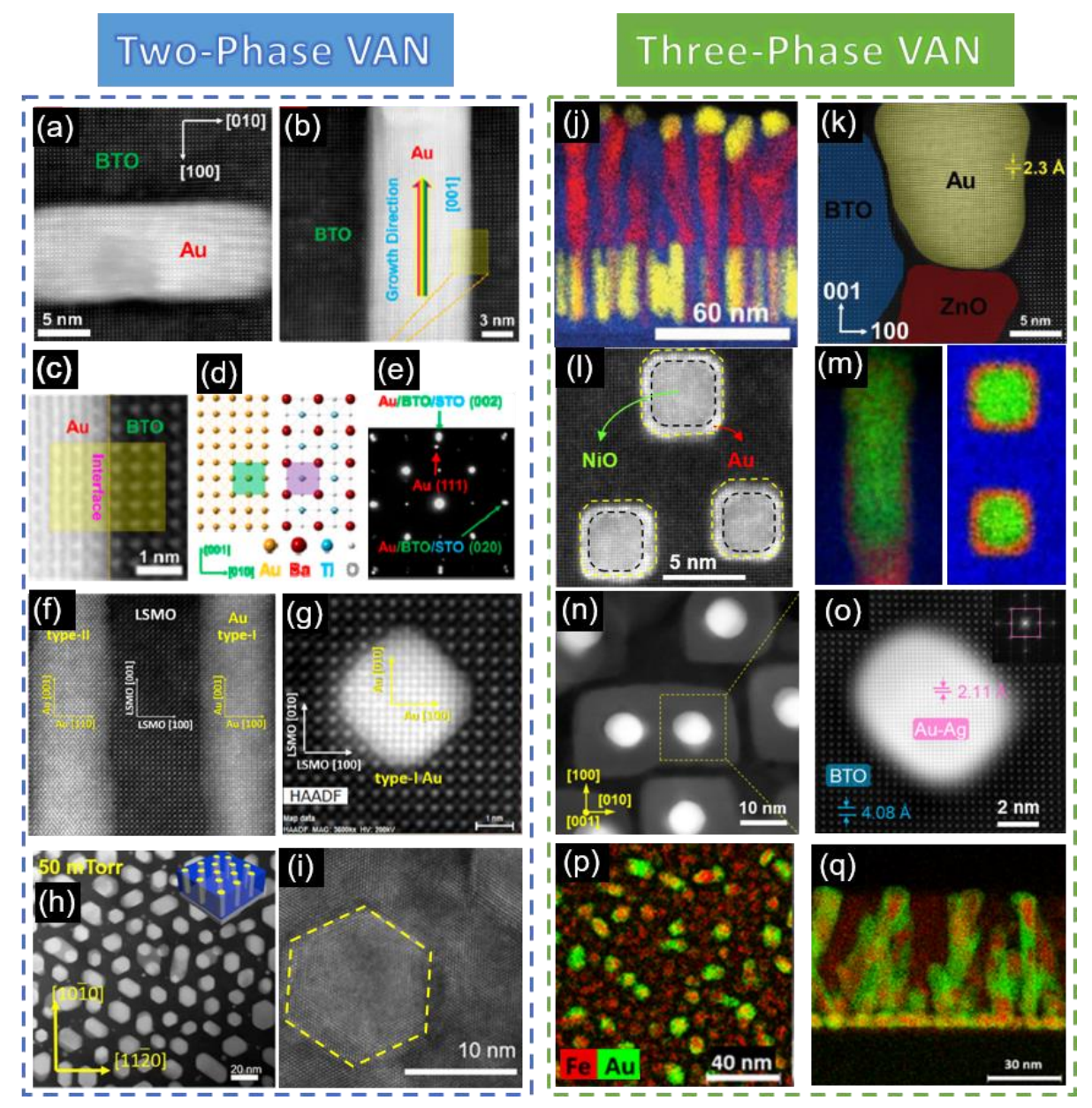

Figure 5. Strain coupling of two-phase and three-phase VANs. (a-e) BTO-Au VAN: (a) plan-view and (b) cross-sectional STEM micrographs at BTO/Au interface [56]. (c,d) HRSTEM micrograph at $\mathrm{BTO} / \mathrm{Au}$ interface and the atomic construction. (e) Diffraction pattern. (f) Cross-sectional and (g) plan-view STEM images of LSMO-Au VAN [68]. (h) Low-magnification plan-view STEM and (i) plan-view HRTEM image of ZnO-Au VAN [65]. (j,k) Cross-sectional EDX mapping and HRSTEM image of BTO-ZnO-Au three-phase VAN [62]. (1) Plan-view HRSTEM and (m) corresponding EDX mapping of TiN-NiO-Au three-phase heterostructure exhibiting core-shell nanopillars [54]. (n,o) Planview STEM images of BTO- $\mathrm{Au}_{x} \mathrm{Ag}_{1-\mathrm{x}}$ VAN [61]. (p) Plan-view and (q) cross-sectional EDX maps of LSFO-Fe-Au three-phase VAN [69]. Reproduced with permission, Wiley and ACS Publications.

Another type of complex heterostructure is simply through the mixing or alloying of two metallic components, such as $\mathrm{Au}_{\mathrm{x}} \mathrm{Ag}_{1-\mathrm{x}}$ alloy to lower the ohmic loss or to enhance the plasmonic resonance through introducing $\mathrm{Ag}$ [84], as well as the Au-Fe mixture to enhance the magneto-optical coupling via involving a magnetic phase [69]. The BTO$\mathrm{Au}_{\mathrm{x}} \mathrm{Ag}_{1-\mathrm{x}} \mathrm{VAN}$ in Figure 5n,o displays an interesting nano-domino-like structure, where the strain energy from $\mathrm{Au}_{\mathrm{x}} \mathrm{Ag}_{1-\mathrm{x}}$ alloyed nanopillars changes the lattice spacing of the surrounding BTO matrix, forming extruded and ordered nanodomains. On the other hand, the $\mathrm{La}_{0.5} \mathrm{Sr}_{0.5} \mathrm{FeO}_{3}-\mathrm{Fe}-\mathrm{Au}$ nanocomposite as shown in Figure $5 \mathrm{p}$, $\mathrm{q}$ demonstrates a successful coupling between $\mathrm{Fe}$ and $\mathrm{Au}$ as relatively well-aligned nanopillars without intermixing, which can be traced to the phase stability and relative weight fraction at the growth temperature. 


\section{Tuning Geometry and Substrate}

Besides optical anisotropy, a wide range of tunabilities has been investigated through the control over geometry or substrate of the ceramic-based VANs. Geometrical control for tunable plasmonics has been extensively reported in chemically grown nanostructures $[85,86]$. Here, by tailoring the growth parameters such as laser frequency, duration of growth, second phase concentration, temperature, oxygen pressure, subsequent tuning of aspect ratio, shape, distribution, and morphology can be effectively realized using PLD [87]. A thickness dependent BTO-Au growth has been reported by Zhang et al [57]. Simply by changing the duration of growth, the aspect ratio of Au nanopillars are tuned from 3.6 to 0.8 , with a morphological change from nanopillar to nanodisk array (Figure 6a). The aspect ratio of $\mathrm{Au}$ is primarily affected by the height of the pillars. As a result, a continuous blue shift of the hyperbolic transition (epsilon-near-zero, ENZ) of the extraordinary dielectric tensors (Figure $6 b, c$ ) is observed, which indicates a change of charge carrier density of the entire heterostructure. Controlling laser frequency for tuning nanocolumn dimensions has been studied in many oxide-oxide VANs [43]. An example shown in Figure 6e-g is the tuning of $\mathrm{ZnO}-\mathrm{Au}$ VAN. Here, reducing the laser frequency lowers the growth rate and allows for a longer resting time of Au adatoms. The resulting nanopillars are much wider and thicker (Figure $5 \mathrm{~d}, \mathrm{f})$. Optical penetration is extremely sensitive to the change of nanoresonators, therefore, effective changes of inter-pillar distance and size both act on tuning of dielectric function (Figure 6e,g). There are certainly other tuning configurations, such as the TiN-Ag metamaterial as shown in Figure 2e [53]. In this study, the angle of $\mathrm{Ag}$ nanopillar is effectively changed from $0^{\circ}$ to $50^{\circ}$ by controlling the growth rate. The tilted resonators realize a strong angular selectivity and nonlinear response over a wide spectrum range, excited by the strong Ag LSP mode with respect to the angle of incident light.

Pillar Height: Thickness

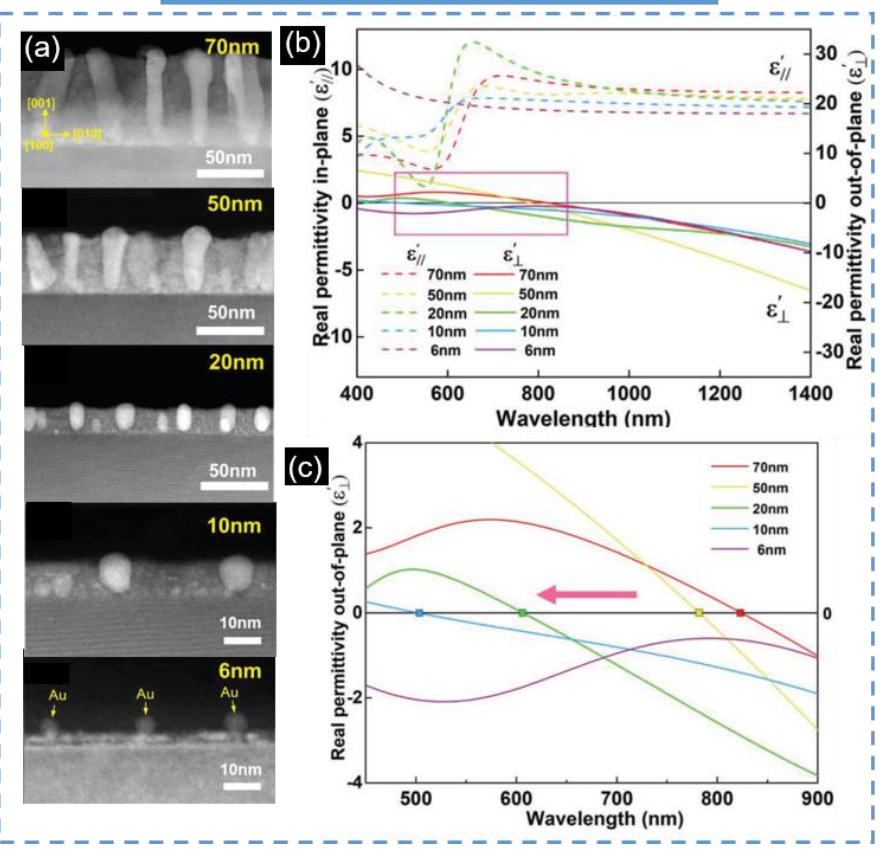

Pillar Diameter: Frequency
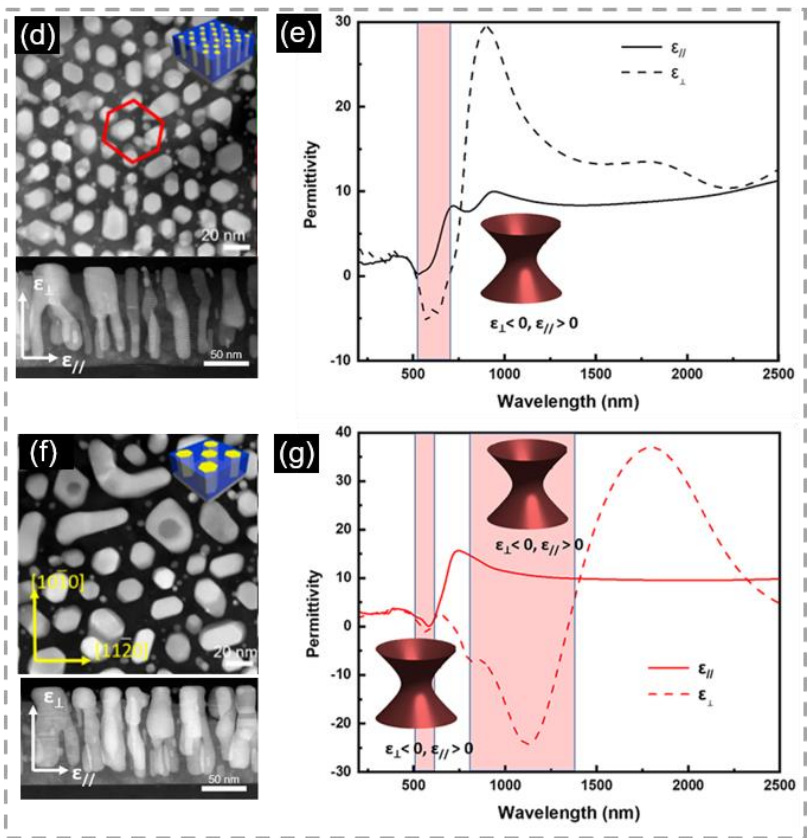

Figure 6. Geometrical tunabilities. (a) BTO-Au with change of film thickness, and effectively, Au phase is tuned from nanopillars to nanodisks. (b,c) Effective tuning of hyperbolic property, OP dielectric tensor exhibits continuous blue shift with reduction of film thickness [57]. (d,f) STEM micrographs of ZnO-Au VAN with tuning of pillar diameter and $(\mathbf{e}, \mathbf{g})$ effective changes of uniaxial dielectric tensors [65]. Reproduced with permission, Wiley and ACS Publications. 
Since bottom-up deposition realizes inch-scale surface coverage and high crystallinity as compared to the existing top-down approaches such as nanolithography, extending the growth on $\mathrm{Si}$ or flexible substrates is extremely crucial toward on-chip and flexible opto-electronic devices [88]. To this end, the growth of BTO-Au VAN has been explored on buffered Si substrate [59]. Here, the TiN/STO $(<20 \mathrm{~nm})$ buffer layer serves as a transition layer to establish the thin film epitaxy on $\mathrm{Si}$ and to enhance the overall growth morphology (Figure 7a). TiN buffered Si integration has been reported in many oxide-oxide systems such as LSMO-NiO [89,90]. Direct nucleation of two-phase nanocomposite would be rather challenging since the surface energy, crystal symmetry, and lattice parameter of Si could be different from oxides and metals. From Figure $7 b-f$, the coupled $X$-ray diffraction (XRD) and TEM results indicate well-distributed Au nanopillars within BTO matrix, while the $\mathrm{BTO} / \mathrm{STO} / \mathrm{TiN} / \mathrm{Si}$ lateral interfaces remain crystalline sharp without interdiffusion.
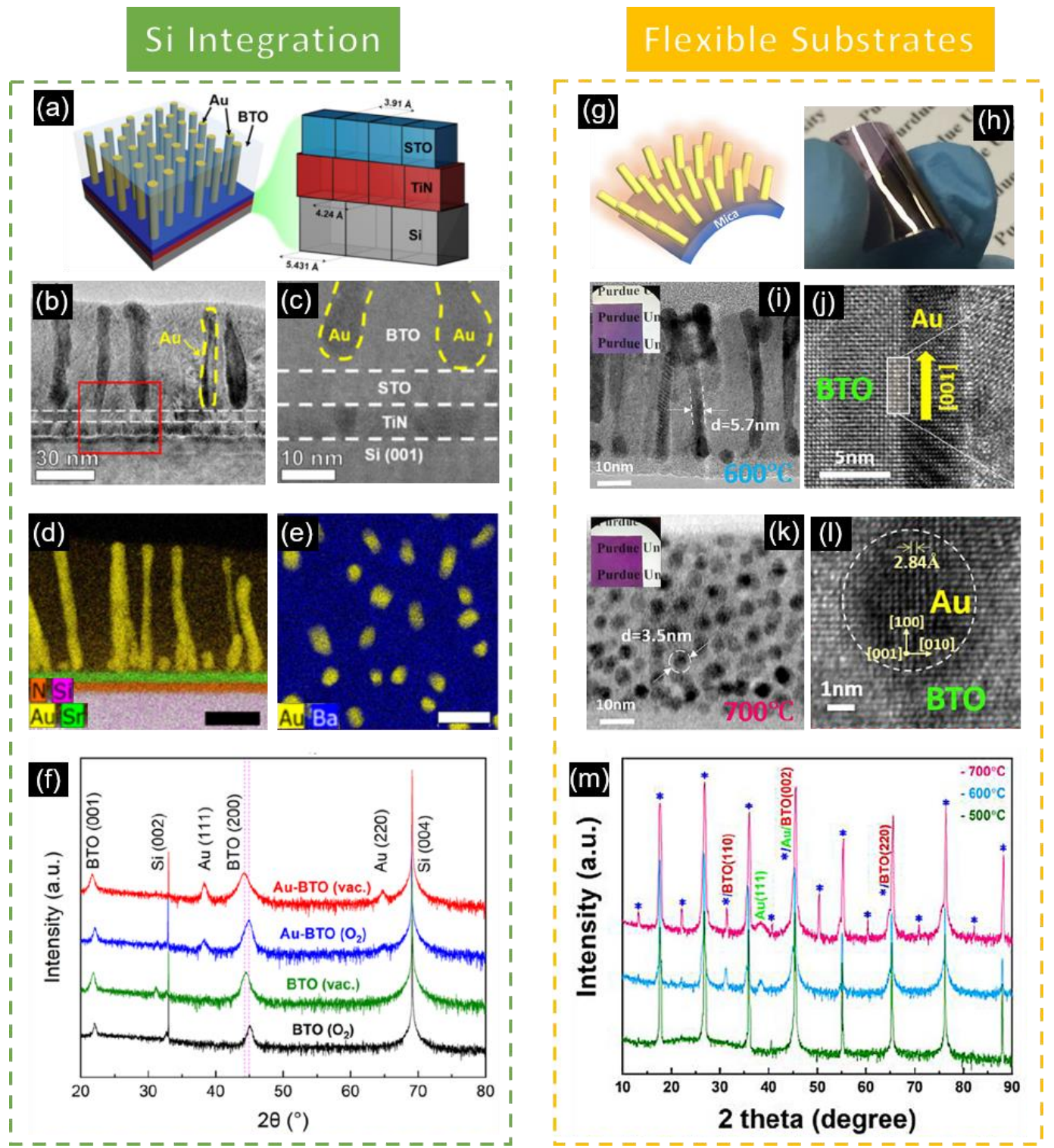

Figure 7. (a-f) BTO-Au VAN integrated on buffered Si substrate [59]. (a) Buffer layer is composed of STO/TiN bilayer. $(\mathbf{b}, \mathbf{c})$ Cross-sectional TEM images of overall microstructure and the lateral interface region, (d) corresponding crosssectional and (e) plan-view EDX maps. (f) XRD $\theta-2 \theta$ scans showing high epitaxial quality. (g-m) BTO-Au VAN integrated on flexible mica substrate [60]. (h) Light reflection image upon bending the sample. (i-j) TEM images of Au nanopillars in BTO matrix showing epitaxial strain coupling. (k,l) TEM images of Au nanoparticle in BTO matrix under higher growth temperature. (m) XRD $\theta-2 \theta$ scans exhibiting high crystalline quality of the films. Reproduced with permission, ACS Publications and Elsevier. 
Flexible muscovite mica, with inter-plane van der Waals bonding, serves as an ideal template to grow functional thin films for wearable and flexible devices [91-93]. Recently, Liu et al. demonstrated the successful integration of BTO-Au VAN directly on mica substrate, with epitaxial growth and sharp atomic interface [60]. At the macroscopic scale, the entire sample is bendable without fracture or failure (Figure 7a,b). Interestingly, the change of growth temperature reflects a morphological transition from nanopillars to nanoparticles, which is potentially owing to the high sensitivity of the nucleation energy of $\mathrm{BTO}$ and $\mathrm{Au}$ with respect to the mica substrate. A relatively stable optical performance is achieved after cycles of concave and convex bending, which is promising for further investigations on material integration and device designs.

\section{Beyond Optical Anisotropy}

The ultimate goals of ceramic-based metamaterial using conventional bottom-up growth are certainly not limited to tunabilities and optical anisotropies. Here, we present few examples on coupling growth designs to realize capabilities such as sensing, magnetooptical coupling, as well as high-temperature plasmonics. As briefly mentioned in the earlier discussion, the design of plasmonic TiN nanoholes is realized through removal of Au phase from a highly-ordered TiN-Au VAN template (Figure 8a) [72]. The nanoscale air holes generate strong LSPs close to the edge of TiN metasurfaces, which are highly sensitive to the change of local refractive indices and can be applied for sensing. The first demonstration of sensing was conducted by coupling the surface with 2D perovskite nanoplates to resolve real-time changes of photoluminescence (PL). Compare to pure TiN film and TiN-Au template, the PL signal from TiN nanoholes with 2D nanoplates exhibits an obvious enhancement, while three new peaks located at 432, 456, and $514 \mathrm{~nm}$ indicate additional recombination states affected by coupling with such defective topology (Figure 8b,c) [94]. For the second demonstration, the transmittance measurement was conducted by dropping the immersion oil with varied refractive index onto the sample surface. An obvious redshift ( 638.56 to $742.21 \mathrm{~nm}$ ) upon the increase of refractive index (1.35 to 1.75) is observed (Figure 8d), indicating a change of surface plasmon (SP) mode corresponding to the local change of refraction index. The calculated figure of merit (FOM) and refractive index unit (RIU) can be enhanced by improving the etching efficiency or by enlarging the size of the nanoholes.

Magneto-optical coupling, on the other hand, plays an important part in realizing ultrafast switching, spintronic devices, and all-optical photonic circuits [95,96]. An intuitive method is to couple magnetic and optical components at nanoscale, in which sense the VAN provides an ideal and promising way to realize such designs. Design of TiN-NiO-Au threephase heterostructure is presented in Figure 8e,f, it shows a magnetic core-plasmonic shell coupling with a high degree of periodicity [54]. The growth mechanism has been explained in the previous section, and as a result, such coupling realizes a strong enhancement of Kerr signal, which also exhibits certain anisotropy owing to the vertically coupled interface. The results indicate a weak ferromagnetic behavior of the $\mathrm{NiO}$ when its dimension reduces to few nanometers. It is noted that the shape of P-MOKE hysteresis is rather irregular owing to the two contributing coupling schemes (Figure 8g), i.e., the coupling between weak ferromagnetic $\mathrm{NiO}$ core and plasmonics $\mathrm{Au}$ shell, as well as the ferromagnetic $\mathrm{Ni}$ nanodomains at the bottom layer.

Another characteristic, which is also crucial in the field of plasmonics, is to design durable nanostructures for solar-cells, biomedical sensors, and quantum computing technologies [34,97-99]. From a materials perspective, metals such as Ag and $\mathrm{Cu}$ exhibit strong surface-enhanced Raman scattering and SP modes, while their poor thermal stability and chemical reactions potentially deteriorate the device performance under environmental fluctuations. By embedding Ag nanopillars in a durable TiN matrix, a strong enhancement of mechanical and thermal stability has been realized. Figure $8 \mathrm{~h}$ shows the STEM and diffraction patterns (DP) of the nanostructure after a heating cycle of $>500{ }^{\circ} \mathrm{C}$ [53]. The TiN/Ag interface remains intact, and the sharp DPs indicate the high crystallinity. 
Interestingly, a tilted Ag nanopillar growth is realized, which results in several interesting features, such as second harmonic generation (SHG) and selective reflectance from UV to mid-infrared regime (Figure 8i), as mentioned earlier.
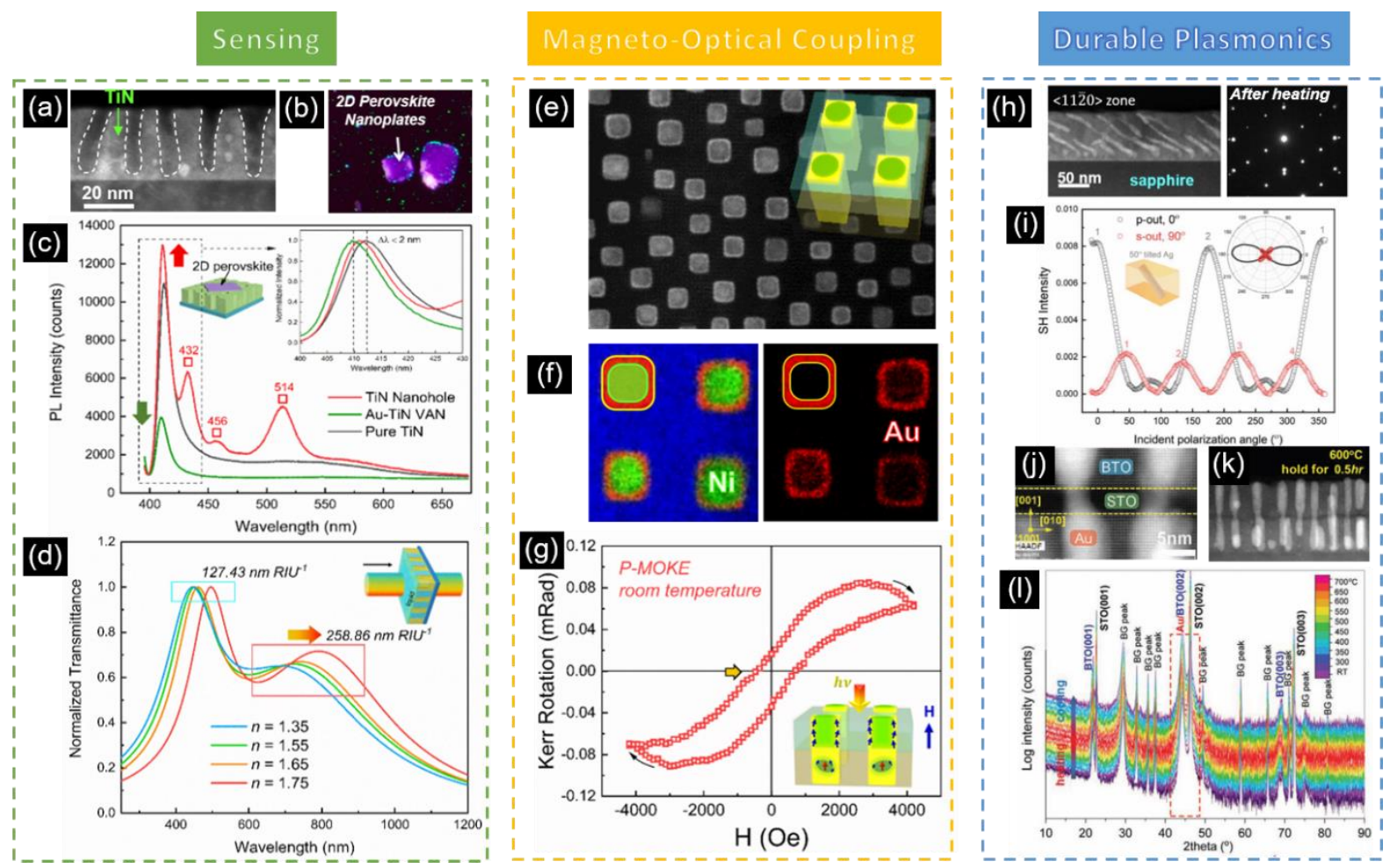

Figure 8. Multifunctionalities. (a) Cross-sectional STEM micrograph of TiN nanohole film [72]. (b) Crystallization of 2D perovskite nanoplates on TiN nanohole surface. (c) PL spectra comparing 2D nanoflakes grown on TiN nanohole, TiN-Au VAN and pure TiN film. (d) Refractive index sensing of TiN nanohole film. (e) Plan-view STEM micrograph of TiN-NiO-Au three-phase VAN showing highly ordered core-shell nanopillars [54]. (f) EDX mapping of Ni (green), Au (red) and Ti (blue). (g) P-MOKE hysteresis loop. (h) STEM morphology and DPs of TiN-Ag metamaterial after heating of above $500{ }^{\circ} \mathrm{C}$ [53]. (i) SHG pattern of TiN-Ag. (j) HRSTEM image of STO interlayered BTO-Au sandwich [76]. (k) STEM micrograph upon in-situ heating at $600{ }^{\circ} \mathrm{C}$. (1) Ex-situ XRD patterns with changes of temperature. Reproduced with permission, ACS Publications and Wiley.

Another consideration is the thermal stability at ceramic/metal interface. There are few studies investigating the thermal stability of some oxide-metal VANs, which have provided some promising feedback. For example, a complex interlayered BTO$\mathrm{Au} / \mathrm{STO} / \mathrm{BTO}-\mathrm{Au}$ heterostructure is displayed in Figure 8j [76]. In-situ thermal stability test is conducted inside a TEM column where no obvious morphological change is observed upon $600{ }^{\circ} \mathrm{C}$ annealing. Additional temperature dependent ex-situ XRD characterizations indicate highly stable diffraction peaks without obvious change of position or full-width half maximum (FWHM) values. Though the demonstrated high thermal stability may not be applicable to some systems involving unstable metals (e.g., $\mathrm{Al}, \mathrm{Cu}$ ), these studies on oxide-Au present clear evidence that the Au contained VAN structures are suitable for high-temperature plasmonics.

\section{Challenges and Opportunities}

As an alternative fabrication of top-down lithographic patterning, the bottom-up growth by self-assembling of two or more functional phases realizes comparable geometry as wire metamaterials, meanwhile possessing a wide range of tunabilities in terms of geometry, materials, and functionalities. Besides the common dielectric-metal designs, novel heterostructures, such as TiN nanohole, all-ceramic VAN (TiN-NiO), three-phase 
coupling (BTO-ZnO-Au), and highly ordered core-shell nanopillars, can realize extreme optical anisotropy, magneto-optical coupling, as well as microfluidic sensing. These designs pave the way for advanced artificial metamaterials in overcoming challenges such as thermal instability, inhomogeneity, ohmic losses. Originating from thin film sciences, the growth of functional nanocomposites using conventional method presents fascinating prospects for next-generation nanophotonics and spintronics. Meanwhile, there are still remaining challenges to be resolved.

Structural optimization: Aside from multiple interesting and novel coupling schemes that present outstanding flexibility and additional advantages over top-down approaches, most of the reported structures are still at an early stage. Thus, there are several questions or concerns that demand additional exploration, both experimentally and theoretically. How is the reproducibility of the VAN growth? How can we improve the uniformity and periodicity of the nanopillars? Is there any intermixing at the vertical interface? Indeed, improving uniformity is one of the most urgent tasks. From the cross-section STEM micrographs, there are always observable nanopillars nucleated at the initial growth stage, but stopped in the middle of the growth, resulting in dense nanoparticles at the bottom section of the film. From the top-view, the distribution of the nanopillars is not as ideal as the EBL patterned features, as there is always inhomogeneity related to either shape or diameter. These factors become more serious when extending the growth to other substrates or involving multiple phases, when the strain and surface energy add extra perturbations to the growth. Therefore, optimizing the quality of the VAN structure by carefully exploring the growth parameters and related material properties, adding additional processing to facilitate ordering, and coupling with theoretical models to predict the strain and growth condition are some valuable future directions. Improving the periodicity using a highly ordered template, substrate treatment, and defect assisted nucleation have been demonstrated as effective methods [54,100,101].

Toward nanodevices: How to effectively implement such novel heterostructures into practical devices or applications is another challenge to address. Effective tuning of physical properties, such as plasmonic resonance, hyperbolic transition, magneto-optical coupling, magnetic hysteresis, and thermal stability, have been demonstrated, however, these studies are limited to fundamental research. Compared to continuous pure films, involving more interfaces could potentially bring defects, strain, or instability that could cause light scattering, current leakage or tunneling, and intermixing, especially upon environmental fluctuations. In parallel of investigating those potential issues, one can take advantage of such as-grown metamaterials to realize nanoscale coupling of multifunctional phases with inch-scale coverage, to avoid redundant fabrication processes and achieve mass-production of nanodevices. So far, some successful demonstrations of sensing have been achieved, including TiN-Au metasurface for chemical bonding detection [70], microfluidic sensing using TiN nanoholes [72], and TiN-Ag nanocomposite as a high-temperature angular reflector [53]. These studies present great potential and pave the way for applying similar tests to other oxide-metal VANs systems.

The current fabrication of nanodevices rely heavily on lithography techniques. To implement these ceramic-metal VANs for future applications such as spintronics, tunneling junctions, magneto-optical switching, or high-temperature sensors, there are two major advantages to consider. First, bottom-up self-assembly allows the coupling of a wide range of material candidates within metal and ceramic families. If the growth parameters for a specific VAN configuration (e.g., density, aspect ratio) can be traced according to extensive experimental results using a computing or modeling method, many possible VAN systems $(A+B)$ can be easily designed and fabricated. Such self-assembled nanostructures could minimize the complexity or cost of fabrication. Toward complex nanodevice designs such as the already demonstrated double-fishnet hyperbolic metamaterial or patterned tunnel junctions [18,102], these natural two-phase or multiphase geometries, including VAN, nanoparticle-in-matrix, or superlattice structure, can be ideal templates to be coupled with nanolithography methods toward plasmonics metamaterial designs. 
Author Contributions: Conceptualization, X.W. and H.W.; writing-original draft preparation, X.W.; writing-review and editing, X.W. and H.W.; funding acquisition, H.W. All authors have read and agreed to the published version of the manuscript.

Funding: The review covers a wide range of metal-oxide nanocomposite systems that were supported the U.S. Department of Energy, Office of Science, Basic Energy Sciences under Award DE-SC0020077. X.W. and H.W. acknowledge the funding support from U.S. National Science Foundation, DMR2016453 for nitride VANs and DMR-1565822 for oxide-oxide VANs.

Institutional Review Board Statement: Not applicable.

Informed Consent Statement: Not applicable.

Conflicts of Interest: The authors declare no conflict of interest.

\section{References}

1. Niu, S.; Joe, G.; Zhao, H.; Zhou, Y.; Orvis, T.; Huyan, H.; Salman, J.; Mahalingam, K.; Urwin, B.; Wu, J.; et al. Giant optical anisotropy in a quasi-one-dimensional crystal. Nat. Photonics 2018, 12, 392-396. [CrossRef]

2. Che, M.; Li, Z.-Y.; Liu, R.-J. Tunable optical anisotropy in three-dimensional photonic crystals. Phys. Rev. A 2007, 76, 023809. [CrossRef]

3. Kosaka, H.; Kawashima, T.; Tomita, A.; Notomi, M.; Tamamura, T.; Sato, T.; Kawakami, S. Superprism phenomena in photonic crystals. Phys. Rev. B 1998, 58, R10096-R10099. [CrossRef]

4. Karpinski, P.; Shvedov, V.; Krolikowski, W.; Hnatovsky, C. Engineering optical anisotropy in nonlinear crystals with ultrafast light. J. Appl. Phys. 2020, 127, 153104. [CrossRef]

5. Mao, N.; Tang, J.; Xie, L.; Wu, J.; Han, B.; Lin, J.; Deng, S.; Ji, W.; Xu, H.; Liu, K.; et al. Optical Anisotropy of Black Phosphorus in the Visible Regime. J. Am. Chem. Soc. 2016, 138, 300-305. [CrossRef] [PubMed]

6. Huang, S.; Tatsumi, Y.; Ling, X.; Guo, H.; Wang, Z.; Watson, G.; Puretzky, A.A.; Geohegan, D.B.; Kong, J.; Li, J.; et al. In-Plane Optical Anisotropy of Layered Gallium Telluride. ACS Nano 2016, 10, 8964-8972. [CrossRef] [PubMed]

7. Ermolaev, G.A.; Grudinin, D.V.; Stebunov, Y.V.; Voronin, K.V.; Kravets, V.G.; Duan, J.; Mazitov, A.B.; Tselikov, G.I.; Bylinkin, A.; Yakubovsky, D.I.; et al. Giant optical anisotropy in transition metal dichalcogenides for next-generation photonics. Nat. Commun. 2021, 12, 854. [CrossRef]

8. Elser, J.; Wangberg, R.; Podolskiy, V.A.; Narimanov, E.E. Nanowire metamaterials with extreme optical anisotropy. Appl. Phys. Lett. 2006, 89, 261102. [CrossRef]

9. Ren, M.; Plum, E.; Xu, J.; Zheludev, N.I. Giant nonlinear optical activity in a plasmonic metamaterial. Nat. Commun. 2012, 3, 833. [CrossRef]

10. Kadic, M.; Milton, G.W.; van Hecke, M.; Wegener, M. 3D metamaterials. Nat. Rev. Phys. 2019, 1, 198-210. [CrossRef]

11. Poddubny, A.; Iorsh, I.; Belov, P.; Kivshar, Y. Hyperbolic metamaterials. Nat. Photonics 2013, 7, 948-957. [CrossRef]

12. Shekhar, P.; Atkinson, J.; Jacob, Z. Hyperbolic metamaterials: Fundamentals and applications. Nano Converg. 2014, 1, 14. [CrossRef]

13. Huo, P.; Zhang, S.; Liang, Y.; Lu, Y.; Xu, T. Hyperbolic Metamaterials and Metasurfaces: Fundamentals and Applications. Adv. Opt. Mater. 2019, 7, 1801616. [CrossRef]

14. Fang, A.; Koschny, T.; Soukoulis, C.M. Optical anisotropic metamaterials: Negative refraction and focusing. Phys. Rev. B 2009, 79, 245127. [CrossRef]

15. Shalaev, V.M. Optical negative-index metamaterials. Nat. Photonics 2007, 1, 41-48. [CrossRef]

16. Soukoulis, C.M.; Wegener, M. Past achievements and future challenges in the development of three-dimensional photonic metamaterials. Nat. Photonics 2011, 5, 523-530. [CrossRef]

17. Lu, D.; Kan, J.J.; Fullerton, E.E.; Liu, Z. Enhancing spontaneous emission rates of molecules using nanopatterned multilayer hyperbolic metamaterials. Nat. Nanotechnol. 2014, 9, 48-53. [CrossRef] [PubMed]

18. Valentine, J.; Zhang, S.; Zentgraf, T.; Ulin-Avila, E.; Genov, D.A.; Bartal, G.; Zhang, X. Three-dimensional optical metamaterial with a negative refractive index. Nature 2008, 455, 376-379. [CrossRef]

19. Feng, K.; Harden, G.; Sivco, D.L.; Hoffman, A.J. Subdiffraction Confinement in All-Semiconductor Hyperbolic Metamaterial Resonators. ACS Photonics 2017, 4, 1621-1626. [CrossRef]

20. Chanda, D.; Shigeta, K.; Gupta, S.; Cain, T.; Carlson, A.; Mihi, A.; Baca, A.J.; Bogart, G.R.; Braun, P.; Rogers, J.A. Large-area flexible 3D optical negative index metamaterial formed by nanotransfer printing. Nat. Nanotechnol. 2011, 6, 402-407. [CrossRef] [PubMed]

21. Kruk, S.S.; Powell, D.A.; Minovich, A.; Neshev, D.N.; Kivshar, Y.S. Spatial dispersion of multilayer fishnet metamaterials. Opt. Express 2012, 20, 15100-15105. [CrossRef]

22. Simovski, C.R.; Belov, P.A.; Atrashchenko, A.V.; Kivshar, Y.S. Wire Metamaterials: Physics and Applications. Adv. Mater. 2012, 24, 4229-4248. [CrossRef]

23. Yao, J.; Liu, Z.; Liu, Y.; Wang, Y.; Sun, C.; Bartal, G.; Stacy, A.M.; Zhang, X. Optical Negative Refraction in Bulk Metamaterials of Nanowires. Science 2008, 321, 930. [CrossRef] [PubMed]

24. Huang, Z.; Meng, G.; Huang, Q.; Chen, B.; Zhu, C.; Zhang, Z. Large-area Ag nanorod array substrates for SERS: AAO templateassisted fabrication, functionalization, and application in detection PCBs. J. Raman Spectrosc. 2013, 44, 240-246. [CrossRef]

25. Ji, W.; Luo, J.; Lai, Y. Extremely anisotropic epsilon-near-zero media in waveguide metamaterials. Opt. Express 2019, 27, 19463-19473. [CrossRef] [PubMed] 
26. Henzie, J.; Lee, M.H.; Odom, T.W. Multiscale patterning of plasmonic metamaterials. Nat. Nanotechnol. 2007,2 , 549-554. [CrossRef] [PubMed]

27. Escobedo, C. On-chip nanohole array based sensing: A review. Lab Chip 2013, 13, 2445-2463. [CrossRef] [PubMed]

28. Ai, B.; Wang, Z;; Möhwald, H.; Zhang, G. Plasmonic Nanochemistry Based on Nanohole Array. ACS Nano 2017, 11, 12094-12102. [CrossRef]

29. Im, H.; Lee, S.H.; Wittenberg, N.J.; Johnson, T.W.; Lindquist, N.C.; Nagpal, P.; Norris, D.J.; Oh, S.-H. Template-Stripped Smooth Ag Nanohole Arrays with Silica Shells for Surface Plasmon Resonance Biosensing. ACS Nano 2011, 5, $6244-6253$. [CrossRef] [PubMed]

30. Silva, A.; Monticone, F.; Castaldi, G.; Galdi, V.; Alù, A.; Engheta, N. Performing Mathematical Operations with Metamaterials. Science 2014, 343, 160-163. [CrossRef]

31. Zangeneh-Nejad, F.; Sounas, D.L.; Alù, A.; Fleury, R. Analogue computing with metamaterials. Nat. Rev. Mater. 2021, 6, 207-225. [CrossRef]

32. Chen, H.-T.; Padilla, W.J.; Zide, J.M.O.; Gossard, A.C.; Taylor, A.J.; Averitt, R.D. Active terahertz metamaterial devices. Nature 2006, 444, 597-600. [CrossRef] [PubMed]

33. Kapitanova, P.V.; Ginzburg, P.; Rodríguez-Fortuño, F.J.; Filonov, D.S.; Voroshilov, P.M.; Belov, P.A.; Poddubny, A.N.; Kivshar, Y.S.; Wurtz, G.A.; Zayats, A.V. Photonic spin Hall effect in hyperbolic metamaterials for polarization-controlled routing of subwavelength modes. Nat. Commun. 2014, 5, 3226. [CrossRef]

34. Kumar, J.; Liz-Marzán, L.M. Recent Advances in Chiral Plasmonics-Towards Biomedical Applications. Bull. Chem. Soc. Jpn. 2019, 92, 30-37. [CrossRef]

35. Lee, Y.Y.; Kim, R.M.; Im, S.W.; Balamurugan, M.; Nam, K.T. Plasmonic metamaterials for chiral sensing applications. Nanoscale 2020, 12, 58-66. [CrossRef] [PubMed]

36. Boltasseva, A.; Shalaev, V.M. Fabrication of optical negative-index metamaterials: Recent advances and outlook. Metamaterials 2008, 2, 1-17. [CrossRef]

37. Chen, Y. Nanofabrication by electron beam lithography and its applications: A review. Microelectron. Eng. 2015, 135, 57-72. [CrossRef]

38. Lin, C.-H.; Kang, C.-Y.; Wu, T.-Z.; Tsai, C.-L.; Sher, C.-W.; Guan, X.; Lee, P.-T.; Wu, T.; Ho, C.-H.; Kuo, H.-C.; et al. Giant Optical Anisotropy of Perovskite Nanowire Array Films. Adv. Funct. Mater. 2020, 30, 1909275. [CrossRef]

39. Hao, Q.; Huang, H.; Fan, X.; Hou, X.; Yin, Y.; Li, W.; Si, L.; Nan, H.; Wang, H.; Mei, Y.; et al. Facile design of ultra-thin anodic aluminum oxide membranes for the fabrication of plasmonic nanoarrays. Nanotechnology 2017, 28, 105301. [CrossRef]

40. Gao, J.; Sun, L.; Deng, H.; Mathai, C.J.; Gangopadhyay, S.; Yang, X. Experimental realization of epsilon-near-zero metamaterial slabs with metal-dielectric multilayers. Appl. Phys. Lett. 2013, 103, 051111. [CrossRef]

41. Huang, J.; Zhang, D.; Wang, H. Epitaxial TiN/MgO multilayers with ultrathin TiN and MgO layers as hyperbolic metamaterials in visible region. Mater. Today Phys. 2021, 16, 100316. [CrossRef]

42. MacManus-Driscoll, J.L.; Foltyn, S.R.; Jia, Q.X.; Wang, H.; Serquis, A.; Civale, L.; Maiorov, B.; Hawley, M.E.; Maley, M.P.; Peterson, D.E. Strongly enhanced current densities in superconducting coated conductors of $\mathrm{YBa}_{2} \mathrm{Cu}_{3} \mathrm{O}_{7-\mathrm{x}}+\mathrm{BaZrO}_{3}$. Nat. Mater. 2004, 3, 439-443. [CrossRef]

43. Chen, A.; Bi, Z.; Tsai, C.-F.; Lee, J.; Su, Q.; Zhang, X.; Jia, Q.; MacManus-Driscoll, J.L.; Wang, H. Tunable Low-Field Magnetoresistance in $\left(\mathrm{La}_{0.7} \mathrm{Sr}_{0.3} \mathrm{MnO}_{3}\right)_{0.5}:(\mathrm{ZnO})_{0.5}$ Self-Assembled Vertically Aligned Nanocomposite Thin Films. Adv. Funct. Mater. 2011, 21, 2423-2429. [CrossRef]

44. Yang, H.; Wang, H.; Yoon, J.; Wang, Y.; Jain, M.; Feldmann, D.M.; Dowden, P.C.; MacManus-Driscoll, J.L.; Jia, Q. Vertical Interface Effect on the Physical Properties of Self-Assembled Nanocomposite Epitaxial Films. Adv. Mater. 2009, 21, 3794-3798. [CrossRef]

45. MacManus-Driscoll, J.L. Self-Assembled Heteroepitaxial Oxide Nanocomposite Thin Film Structures: Designing InterfaceInduced Functionality in Electronic Materials. Adv. Funct. Mater. 2010, 20, 2035-2045. [CrossRef]

46. MacManus-Driscoll, J.L.; Zerrer, P.; Wang, H.; Yang, H.; Yoon, J.; Fouchet, A.; Yu, R.; Blamire, M.G.; Jia, Q. Strain control and spontaneous phase ordering in vertical nanocomposite heteroepitaxial thin films. Nat. Mater. 2008, 7, 314-320. [CrossRef] [PubMed]

47. Zhang, W.; Chen, A.; Bi, Z.; Jia, Q.; MacManus-Driscoll, J.L.; Wang, H. Interfacial coupling in heteroepitaxial vertically aligned nanocomposite thin films: From lateral to vertical control. Curr. Opin. Solid State Mater. Sci. 2014, 18, 6-18. [CrossRef]

48. Zhang, W.; Ramesh, R.; MacManus-Driscoll, J.L.; Wang, H. Multifunctional, self-assembled oxide nanocomposite thin films and devices. MRS Bull. 2015, 40, 736-745. [CrossRef]

49. Huang, J.; MacManus-Driscoll, J.L.; Wang, H. New epitaxy paradigm in epitaxial self-assembled oxide vertically aligned nanocomposite thin films. J. Mater. Res. 2017, 32, 4054-4066. [CrossRef]

50. Ohring, M. Chapter 7-Substrate Surfaces and Thin-Film Nucleation. In Materials Science of Thin Films, 2nd ed.; Ohring, M., Ed.; Academic Press: San Diego, CA, USA, 2002; pp. 357-415.

51. Gao, J.; Wu, X.; Li, Q.; Du, S.; Huang, F.; Liang, L.; Zhang, H.; Zhuge, F.; Cao, H.; Song, Y. Template-Free Growth of Well-Ordered Silver Nano Forest/Ceramic Metamaterial Films with Tunable Optical Responses. Adv. Mater. 2017, 29, 1605324. [CrossRef]

52. Huang, J.; Wang, X.; Hogan, N.L.; Wu, S.; Lu, P.; Fan, Z.; Dai, Y.; Zeng, B.; Starko-Bowes, R.; Jian, J.; et al. Nanoscale Artificial Plasmonic Lattice in Self-Assembled Vertically Aligned Nitride-Metal Hybrid Metamaterials. Adv. Sci. 2018, 5, 1800416. [CrossRef]

53. Wang, X.; Jian, J.; Zhou, Z.; Fan, C.; Dai, Y.; Li, L.; Huang, J.; Sun, J.; Donohue, A.; Bermel, P.; et al. Self-Assembled Ag-TiN Hybrid Plasmonic Metamaterial: Tailorable Tilted Nanopillar and Optical Properties. Adv. Opt. Mater. 2019, 7, 1801180. [CrossRef]

54. Wang, X.; Jian, J.; Wang, H.; Liu, J.; Pachaury, Y.; Lu, P.; Rutherford, B.X.; Gao, X.; Xu, X.; El-Azab, A.; et al. Nitride-Oxide-Metal Heterostructure with Self-Assembled Core-Shell Nanopillar Arrays: Effect of Ordering on Magneto-Optical Properties. Small 2021, 17, 2007222. [CrossRef] 
55. Vitos, L.; Ruban, A.V.; Skriver, H.L.; Kollár, J. The surface energy of metals. Surf. Sci. 1998, 411, 186-202. [CrossRef]

56. Li, L.; Sun, L.; Gomez-Diaz, J.S.; Hogan, N.L.; Lu, P.; Khatkhatay, F.; Zhang, W.; Jian, J.; Huang, J.; Su, Q.; et al. SelfAssembled Epitaxial Au-Oxide Vertically Aligned Nanocomposites for Nanoscale Metamaterials. Nano Lett. 2016, 16, 3936-3943. [CrossRef] [PubMed]

57. Zhang, D.; Misra, S.; Li, L.; Wang, X.; Jian, J.; Lu, P.; Gao, X.; Sun, X.; Qi, Z.; Kalaswad, M.; et al. Tunable Optical Properties in SelfAssembled Oxide-Metal Hybrid Thin Films via Au-Phase Geometry Control: From Nanopillars to Nanodisks. Adv. Opt. Mater. 2019, 8, 1901359. [CrossRef]

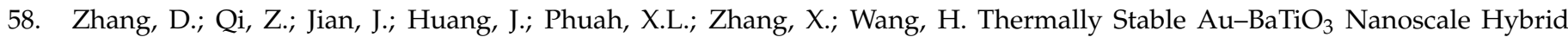
Metamaterial for High-Temperature Plasmonic Applications. ACS Appl. Nano Mater. 2020, 3, 1431-1437. [CrossRef]

59. Kalaswad, M.; Zhang, D.; Gao, X.; Contreras, L.L.; Wang, H.; Wang, X.; Wang, H. Integration of Hybrid Plasmonic Au-BaTiO 3 Metamaterial on Silicon Substrates. ACS Appl. Mater. Interfaces 2019, 11, 45199-45206. [CrossRef] [PubMed]

60. Liu, J.; Wang, X.; Gao, X.; Wang, H.; Jian, J.; Huang, J.; Sun, X.; Qi, Z.; Misra, S.; He, Z.; et al. Multifunctional self-assembled $\mathrm{BaTiO}_{3}-\mathrm{Au}$ nanocomposite thin films on flexible mica substrates with tunable optical properties. Appl. Mater. Today 2020, 21, 100856. [CrossRef]

61. Zhang, D.; Misra, S.; Jian, J.; Lu, P.; Li, L.; Wissel, A.; Zhang, X.; Wang, H. Self-Assembled BaTiO ${ }_{3}-\mathrm{Au}_{\mathrm{x}} \mathrm{Ag}_{1-\mathrm{x}} \mathrm{Low}_{-\mathrm{Loss}} \mathrm{Hybrid}$ Plasmonic Metamaterials with an Ordered "Nano-Domino-like" Microstructure. ACS Appl. Mater. Interfaces 2021, 13, 5390-5398. [CrossRef] [PubMed]

62. Misra, S.; Li, L.; Zhang, D.; Jian, J.; Qi, Z.; Fan, M.; Chen, H.-T.; Zhang, X.; Wang, H. Self-Assembled Ordered Three-Phase Au-BaTiO 3 -ZnO Vertically Aligned Nanocomposites Achieved by a Templating Method. Adv. Mater. 2019, 31, 1806529. [CrossRef]

63. Misra, S.; Zhang, D.; Lu, P.; Wang, H. Thermal stability of self-assembled ordered three-phase Au-BaTiO $3-\mathrm{ZnO}_{3}$ nanocomposite thin films via in situ heating in TEM. Nanoscale 2020, 12, 23673-23681. [CrossRef] [PubMed]

64. Misra, S.; Zhang, D.; Qi, Z.; Li, D.; Lu, J.; Chen, H.-T.; Wang, H. Morphology Control of Self-Assembled Three-Phase Au-BaTiO 3 ZnO Hybrid Metamaterial for Tunable Optical Properties. Cryst. Growth Des. 2020, 20, 6101-6108. [CrossRef]

65. Paldi, R.L.; Sun, X.; Wang, X.; Zhang, X.; Wang, H. Strain-Driven In-plane Ordering in Vertically Aligned ZnO-Au Nanocomposites with Highly Correlated Metamaterial Properties. ACS Omega 2020, 5, 2234-2241. [CrossRef] [PubMed]

66. Paldi, R.L.; Wang, X.; Sun, X.; He, Z.; Qi, Z.; Zhang, X.; Wang, H. Vertically Aligned $\mathrm{Ag}_{\mathrm{x}} \mathrm{Au}_{1-\mathrm{x}}$ Alloyed Nanopillars Embedded in $\mathrm{ZnO}$ as Nanoengineered Low-Loss Hybrid Plasmonic Metamaterials. Nano Lett. 2020, 20, 3778-3785. [CrossRef] [PubMed]

67. Huang, J.; Wang, X.; Phuah, X.L.; Lu, P.; Qi, Z.; Wang, H. Plasmonic Cu nanostructures in ZnO as hyperbolic metamaterial thin films. Mater. Today Nano 2019, 8, 100052. [CrossRef]

68. Huang, J.; Wang, H.; Qi, Z.; Lu, P.; Zhang, D.; Zhang, B.; He, Z.; Wang, H. Multifunctional Metal-Oxide Nanocomposite Thin Film with Plasmonic Au Nanopillars Embedded in Magnetic La ${ }_{0.67} \mathrm{Sr}_{0.33} \mathrm{MnO}_{3}$ Matrix. Nano Lett. 2021, 21, $1032-1039$. [CrossRef] [PubMed]

69. Zhang, B.; Kalaswad, M.; Rutherford, B.X.; Misra, S.; He, Z.; Wang, H.; Qi, Z.; Wissel, A.E.; Xu, X.; Wang, H. Au-Encapsulated Fe Nanorods in Oxide Matrix with Tunable Magneto-Optic Coupling Properties. ACS Appl. Mater. Interfaces 2020, 12, 51827-51836. [CrossRef]

70. Wang, X.J.; Jian, J.; Diaz-Amaya, S.; Kumah, C.E.; Lu, P.; Huang, J.J.; Lim, D.G.; Pol, V.G.; Youngblood, J.P.; Boltasseva, A.; et al. Hybrid plasmonic Au-TiN vertically aligned nanocomposites: A nanoscale platform towards tunable optical sensing. Nanoscale Adv. 2019, 1, 1045-1054. [CrossRef]

71. Wang, X.; Choi, J.; Liu, J.; Malis, O.; Li, X.; Bermel, P.; Zhang, X.; Wang, H. 3D Hybrid Trilayer Heterostructure: Tunable Au Nanorods and Optical Properties. ACS Appl. Mater. Interfaces 2020, 12, 45015-45022. [CrossRef]

72. Wang, X.; Ma, X.; Shi, E.; Lu, P.; Dou, L.; Zhang, X.; Wang, H. Large-Scale Plasmonic Hybrid Framework with Built-In Nanohole Array as Multifunctional Optical Sensing Platforms. Small 2020, 16, 1906459. [CrossRef]

73. Wang, X.; Wang, H.; Jian, J.; Rutherford, B.X.; Gao, X.; Xu, X.; Zhang, X.; Wang, H. Metal-Free Oxide-Nitride Heterostructure as a Tunable Hyperbolic Metamaterial Platform. Nano Lett. 2020, 20, 6614-6622. [CrossRef] [PubMed]

74. Wang, X.; Wang, H. Self-assembled nitride-metal nanocomposites: Recent progress and future prospects. Nanoscale 2020, 12, 20564-20579. [CrossRef] [PubMed]

75. Lee, J.-K.; Hong, K.-S.; Jang, J.-W. Roles of Ba/Ti Ratios in the Dielectric Properties of BaTiO ${ }_{3}$ Ceramics. J. Am. Ceram. Soc. 2001, 84, 2001-2006. [CrossRef]

76. Zhang, D.; Lu, P.; Misra, S.; Wissel, A.; He, Z.; Qi, Z.; Gao, X.; Sun, X.; Liu, J.; Lu, J.; et al. Design of 3D Oxide-Metal Hybrid Metamaterial for Tailorable Light-Matter Interactions in Visible and Near-Infrared Region. Adv. Opt. Mater. 2021, 9, 2001154. [CrossRef]

77. Pearton, S.J.; Norton, D.P.; Ip, K.; Heo, Y.W.; Steiner, T. Recent progress in processing and properties of ZnO. Superlattices Microstruct. 2003, 34, 3-32. [CrossRef]

78. Irwin, M.D.; Buchholz, D.B.; Hains, A.W.; Chang, R.P.H.; Marks, T.J. p-Type semiconducting nickel oxide as an efficiency-enhancing anode interfacial layer in polymer bulk-heterojunction solar cells. Proc. Natl. Acad. Sci. USA 2008, 105, 2783-2787. [CrossRef]

79. Sun, X.; MacManus-Driscoll, J.L.; Wang, H. Spontaneous Ordering of Oxide-Oxide Epitaxial Vertically Aligned Nanocomposite Thin Films. Annu. Rev. Mater. Res. 2020, 50, 229-253. [CrossRef]

80. Xiong, Z.H.; Wu, D.; Valy Vardeny, Z.; Shi, J. Giant magnetoresistance in organic spin-valves. Nature 2004, 427, 821-824. [CrossRef] [PubMed]

81. Kang, B.S.; Wang, H.; MacManus-Driscoll, J.L.; Li, Y.; Jia, Q.X.; Mihut, I.; Betts, J.B. Low field magnetotransport properties of $\left(\mathrm{La}_{0.7} \mathrm{Sr}_{0.3} \mathrm{MnO}_{3}\right)_{0.5}:(\mathrm{ZnO})_{0.5}$ nanocomposite films. Appl. Phys. Lett. 2006, 88, 192514. [CrossRef] 
82. Pinion, C.W.; Nenon, D.P.; Christesen, J.D.; Cahoon, J.F. Identifying Crystallization- and Incorporation-Limited Regimes during Vapor-Liquid-Solid Growth of Si Nanowires. ACS Nano 2014, 8, 6081-6088. [CrossRef]

83. Harmand, J.C.; Patriarche, G.; Péré-Laperne, N.; Mérat-Combes, M.-N.; Travers, L.; Glas, F. Analysis of vapor-liquid-solid mechanism in Au-assisted GaAs nanowire growth. Appl. Phys. Lett. 2005, 87, 203101. [CrossRef]

84. Wang, C.-Y.; Chen, H.-Y.; Sun, L.; Chen, W.-L.; Chang, Y.-M.; Ahn, H.; Li, X.; Gwo, S. Giant colloidal silver crystals for low-loss linear and nonlinear plasmonics. Nat. Commun. 2015, 6, 7734. [CrossRef]

85. Chang, H.-H.; Murphy, C.J. Mini Gold Nanorods with Tunable Plasmonic Peaks beyond 1000 nm. Chem. Mater. 2018, 30, 1427-1435. [CrossRef]

86. Luo, M.; Ruditskiy, A.; Peng, H.-C.; Tao, J.; Figueroa-Cosme, L.; He, Z.; Xia, Y. Penta-Twinned Copper Nanorods: Facile Synthesis via Seed-Mediated Growth and Their Tunable Plasmonic Properties. Adv. Funct. Mater. 2016, 26, 1209-1216. [CrossRef]

87. Chen, A.; Bi, Z.; Jia, Q.; MacManus-Driscoll, J.L.; Wang, H. Microstructure, vertical strain control and tunable functionalities in self-assembled, vertically aligned nanocomposite thin films. Acta Mater. 2013, 61, 2783-2792. [CrossRef]

88. Staude, I.; Schilling, J. Metamaterial-inspired silicon nanophotonics. Nat. Photonics 2017, 11, 274-284. [CrossRef]

89. Huang, J.; Gellatly, A.; Kauffmann, A.; Sun, X.; Wang, H. Exchange Bias Effect along Vertical Interfaces in $\mathrm{La}_{0.7} \mathrm{Sr}_{0.3} \mathrm{MnO}_{3}: \mathrm{NiO}$ Vertically Aligned Nanocomposite Thin Films Integrated on Silicon Substrates. Cryst. Growth Des. 2018, 18, 4388-4394. [CrossRef]

90. Zhang, W.; Chen, A.; Khatkhatay, F.; Tsai, C.-F.; Su, Q.; Jiao, L.; Zhang, X.; Wang, H. Integration of Self-Assembled Vertically Aligned Nanocomposite $\left(\mathrm{La}_{0.7} \mathrm{Sr}_{0.3} \mathrm{MnO}_{3}\right)_{1-\mathrm{x}}:(\mathrm{ZnO})_{\mathrm{x}}$ Thin Films on Silicon Substrates. ACS Appl. Mater. Interfaces 2013, 5, 3995-3999. [CrossRef]

91. Huang, J.; Wang, H.; Wang, X.; Gao, X.; Liu, J.; Wang, H. Exchange Bias in a $\mathrm{La}_{0.67} \mathrm{Sr}_{0.33} \mathrm{MnO}_{3} / \mathrm{NiO}$ Heterointerface Integrated on a Flexible Mica Substrate. ACS Appl. Mater. Interfaces 2020, 12, 39920-39925. [CrossRef] [PubMed]

92. Ma, C.-H.; Lin, J.-C.; Liu, H.-J.; Do, T.H.; Zhu, Y.-M.; Ha, T.D.; Zhan, Q.; Juang, J.-Y.; He, Q.; Arenholz, E.; et al. Van der Waals epitaxy of functional $\mathrm{MoO}_{2}$ film on mica for flexible electronics. Appl. Phys. Lett. 2016, 108, 253104. [CrossRef]

93. Liu, J.; Feng, Y.; Tang, R.; Zhao, R.; Gao, J.; Shi, D.; Yang, H. Mechanically Tunable Magnetic Properties of Flexible SrRuO 3 Epitaxial Thin Films on Mica Substrates. Adv. Electron. Mater. 2018, 4, 1700522. [CrossRef]

94. Chow, P.K.; Jacobs-Gedrim, R.B.; Gao, J.; Lu, T.-M.; Yu, B.; Terrones, H.; Koratkar, N. Defect-Induced Photoluminescence in Monolayer Semiconducting Transition Metal Dichalcogenides. ACS Nano 2015, 9, 1520-1527. [CrossRef]

95. Higo, T.; Man, H.; Gopman, D.B.; Wu, L.; Koretsune, T.; van't Erve, O.M.J.; Kabanov, Y.P.; Rees, D.; Li, Y.; Suzuki, M.-T.; et al. Large magneto-optical Kerr effect and imaging of magnetic octupole domains in an antiferromagnetic metal. Nat. Photonics 2018, 12, 73-78. [CrossRef]

96. Tse, W.-K.; MacDonald, A.H. Giant Magneto-Optical Kerr Effect and Universal Faraday Effect in Thin-Film Topological Insulators. Phys. Rev. Lett. 2010, 105, 057401. [CrossRef] [PubMed]

97. Yu, H.; Peng, Y.; Yang, Y.; Li, Z.-Y. Plasmon-enhanced light-matter interactions and applications. NPJ Comput. Mater. 2019, 5, 45. [CrossRef]

98. Bozhevolnyi, S.I.; Mortensen, N.A. Plasmonics for emerging quantum technologies. Nanophotonics 2017, 6, 1185-1188. [CrossRef]

99. Jang, Y.H.; Jang, Y.J.; Kim, S.; Quan, L.N.; Chung, K.; Kim, D.H. Plasmonic Solar Cells: From Rational Design to Mechanism Overview. Chem. Rev. 2016, 116, 14982-15034. [CrossRef] [PubMed]

100. Choi, H.K.; Aimon, N.M.; Kim, D.H.; Sun, X.Y.; Gwyther, J.; Manners, I.; Ross, C.A. Hierarchical Templating of a $\mathrm{BiFeO}_{3}-\mathrm{CoFe}_{2} \mathrm{O}_{4}$ Multiferroic Nanocomposite by a Triblock Terpolymer Film. ACS Nano 2014, 8, 9248-9254. [CrossRef]

101. Fan, M.; Zhang, B.; Wang, H.; Jian, J.; Sun, X.; Huang, J.; Li, L.; Zhang, X.; Wang, H. Self-Organized Epitaxial Vertically Aligned Nanocomposites with Long-Range Ordering Enabled by Substrate Nanotemplating. Adv. Mater. 2017, 29, 1606861. [CrossRef]

102. Chung, S.-W.; Kishi, T.; Park, J.; Yoshikawa, M.; Park, K.; Nagase, T.; Sunouchi, K.; Kanaya, H.; Kim, G.; Noma, K.; et al. 4Gbit density STT-MRAM using perpendicular MTJ realized with compact cell structure. In Proceedings of the 2016 IEEE International Electron Devices Meeting (IEDM), San Francisco, CA, USA, 3-7 December 2016; pp. 27.21.21-27.21.24. 